\title{
New and improved strategies for the treatment of gout
}

This article was published in the following Dove Press journal: International Journal of Nephrology and Renovascular Disease 22 November 2010

Number of times this article has been viewed

\author{
Natalie Dubchak \\ Gerald F Falasca \\ Division of Rheumatology, Cooper \\ University Hospital, UMDNJ - Robert \\ Wood Johnson Medical School at \\ Camden, Camden, NJ, USA
}

\begin{abstract}
The Western world appears to be in the midst of the third great gout epidemic of all time. In this century, gout is increasing in prevalence despite an increased understanding of its risk factors and pathophysiology, and the availability of reasonably effective treatment. The main cultural factors responsible for this appear to be diet, obesity, ethanol use and medications. Excess fructose consumption is a newly recognized modifiable risk factor. The debate has been renewed concerning hyperuricemia as an independent risk factor for renal insufficiency and cardiovascular disease. Prevention is still rooted in lifestyle choices. Existing treatments have proven to be unsatisfactory in many patients with comorbidities. New treatments are available today and on the horizon for tomorrow, which offer a better quality of life for gout sufferers. These include febuxostat, a nonpurine inhibitor of xanthine oxidase with a potentially better combination of efficacy and safety than allopurinol, and investigational inhibitors of URAT-1, an anion exchanger in the proximal tubule that is critical for uric acid homeostasis. New abortive treatments include interleukin-1 antagonists that can cut short the acute attack in 1 to 2 days in persons who cannot take nonsteroidal anti-inflammatory drugs, colchicine or corticosteroids. Lastly, newer formulations of uricase have the ability to dissolve destructive tophi over weeks or months in patients who cannot use currently available hypouricemic agents. Diagnostically, ultrasound and magnetic resonance imaging offer advanced ways to diagnose gout noninvasively, and just as importantly, a way to follow the progress of tophus dissolution. The close association of hyperuricemia with metabolic syndrome, hypertension and renal insufficiency ensures that nephrologists will see increasing numbers of gout-afflicted patients.
\end{abstract}

Keywords: hyperuricemia, metabolic syndrome, tophi, colchicine, febuxostat, allopurinol

\section{Introduction}

"Be temperate in wine, in eating, girls, and cloth, or the Gout will seize you and plague you ..."

Benjamin Franklin 1706-1790

Studies on the prevalence of gout suggest that we are in the midst of the third great gout epidemic of the Western world. ${ }^{1,2}$ Some of the reasons for this are of particular concern to nephrologists who so commonly must treat gout in persons with renal disease. Reasons for the increase in the prevalence of gout in the past 50 years include first and foremost an increase in the prevalence of metabolic syndrome, which in turn reflects the increase in the average weight of the Western population. Whereas during the golden age of both the Roman and British empires gout was associated with drinking and to a lesser extent lead poisoning, ${ }^{3-5}$ in the present age gout is largely associated with obesity. ${ }^{6-9}$ Other factors are iatrogenic, such as an increase
Correspondence: Gerald F Falasca Division of Rheumatology, 900 Centennial Blvd., Suite 201,Voorhees, NJ 08043, USA $\mathrm{Tel}+\mathrm{I}$ 856-325-6770

$\mathrm{Fax}+\mathrm{I}$ 856-673-45I0

Email falasca-gerald@cooperhealth.edu submit your manuscript $\mid$ www.dovepress.com

Dovepress

DOI: $10.2147 /$ IJNRD.S6048 
in the use of low-dose aspirin (but not high-dose aspirin), ${ }^{10}$ diuretics (very useful medicines in their own right) ${ }^{9}$ and other medications such as cyclosporine, and an increase in the number of organ transplants.

The purposes of this review are several-fold: 1) We will review the first Food and Drug Administration (FDA)-approved hypouricemic agent in 40 years, one that seems to be particularly useful in patients with renal insufficiency. 2) We will review the current data on uricase, a potential treatment for gout that (as the time of writing) has been resubmitted to the FDA for possible approval, and is a treatment that could be particularly useful for those with renal insufficiency. 3) We will review advances in the understanding of both crystal-induced inflammation and renal handling of uric acid. 4) We will review recent additions to the body of knowledge that suggests that hyperuricemia itself contributes independently to the development of hypertension, renal insufficiency and cardiovascular disease. 5) We will review evidence that the two currently available interleukin-1 (IL-1) inhibitors are effective for treatment/prophylaxis of gout attacks. 6) We will review musculoskeletal ultrasound as a useful imaging technique for both the diagnosis of gout and to follow the effects of hypouricemic therapy. 7) We will review evidence suggesting that fructose overconsumption contributes disproportionately to the development of hyperuricemia.

Several factors make the treatment of gout worth reviewing for nephrologists. As mentioned, the prevalence is increasing. Secondly, for the first time in 40 years a new, oral hypouricemic agent (febuxostat; Uloric ${ }^{\circledR}$, Takeda Pharmaceuticals) has been approved in the United States (US), and it seems to be particularly useful in those with renal insufficiency, although data are still limited in this population. ${ }^{11}$ Thirdly, the goal of safely and effectively administering uricase to humans may finally be within reach. ${ }^{12,13}$ Fourthly, nonsteroidal anti-inflammatory drugs (NSAIDs) (never popular among nephrologists, yet a mainstay of treatment for gout among other physicians) are now even less popular because of their recently discovered cardiovascular risks. ${ }^{14}$ Fifthly, the debate as to whether asymptomatic hyperuricemia contributes directly to kidney disease and to cardiovascular risk is again coming to the forefront. ${ }^{15,16}$ Lastly, misconceptions about the treatment of gout unfortunately still abound even among physicians. ${ }^{17}$ Long-term management of gout with lifestyle changes and 3 different classes of medications (those for treatment of the acute attack, those for prophylaxis of attacks and those that reduce body burden of uric acid) can be something of an art. Diagnostically, ultrasound has emerged as a useful tool both to diagnose gout and to follow the effects of hypouricemic treatment. ${ }^{18,19}$

\section{Patient perspectives}

The marked increase in the prevalence of gout in recent years has sparked a number of studies on the quality of life of gouty patients. How do we do at treating gout?

Several studies have documented a lower quality of life among gouty patients. A recent study of gouty patients found that the PCS (Physical Component Summary of the SF-36) was approximately 10 points lower than for the general population. This is twice the threshold of what is considered clinically meaningful. One conclusion of the study was that the current treatment of gout appears to be suboptimal in that nearly half of the patients in the study were experiencing three or more gout flares per year, despite $>80 \%$ of the patients chronically receiving allopurinol. It was hypothesized that physicians may not view the impact of gout nearly as severely as do patients. ${ }^{20}$ It is not entirely clear that this is due to gout alone. Gouty patients have on average a larger number of comorbidities. This was documented recently among veterans ${ }^{21,22}$ but in other studies lower quality persists after adjustment for comorbidities. ${ }^{23}$

A recent review of 2 systematic reviews performed by the Cochrane Musculoskeletal Group highlighted the lack of randomized controlled trials regarding treatment options for acute gout. One conclusion was that colchicine provided a lower quality of life because it almost always causes diarrhea at effective doses, and has a slower onset of action at doses that avoid gastrointestinal distress. ${ }^{24}$

As pointed out by Kim and Choi, recent studies suggest that the majority of gouty patients are not adequately managed with currently available gout treatments. ${ }^{25}$ Shulten found that physicians do not recommend adequate dietary changes to many persons with gout. ${ }^{26}$

It has been further pointed out that serum uric acid is the usual endpoint used in gout treatment trials, ${ }^{25}$ whereas the FDA is now recommending use of patient-reported outcome instruments as effectiveness endpoints in clinical trials. Patients are more interested in the number and severity of gout attacks rather than keeping their uric acid level low. This helps to explain the often poor patient compliance with hypouricemic therapy. It is worth noting in this regard that (despite our efforts at education) patients often perceive hypouricemic therapy as causing more gout instead of less, adding to noncompliance.

In summary, there continue to be abundant opportunities to improve the outcomes of this disease.

\section{Risk factors}

The prevalence of gout increases approximately four-fold to $4.1 \%$ by the age of 75 years. ${ }^{27}$ The risk of developing gout is closely related to the serum uric acid (sUA) level, ${ }^{28}$ yet most 
persons with hyperuricemia never develop clinically evident gout. In one large study, the 5-year risk of gout varied from $0.6 \%$ for those with a serum uric acid level $<7 \mathrm{mg} / \mathrm{dL}$ to $30.5 \%$ for those with a level $\geq 10 \mathrm{mg} / \mathrm{dL}$. The prevalence of hyperuricemia varies with factors such as age, gender, body mass index, blood pressure and renal function. Women are relatively protected until menopause, at which time the incidence of gout increases, a phenomenon that is attributed to loss of estrogen effect (with resulting increase in serum uric acid level), but the exact pathophysiology is unclear. ${ }^{29,30}$

Gout is closely associated with metabolic syndrome consisting of insulin resistance, obesity, hypertension and hypertriglyceridemia. ${ }^{1}$ The magnitude of this association bears emphasis. In one cohort study, the prevalence of the metabolic syndrome was $43.6 \%$ in those with gout versus $5.2 \%$ in the general population. ${ }^{31}$ Both hyperuricemia and metabolic syndrome are associated with abdominal girth as an independent risk factor. ${ }^{32}$ Hypertriglyceridemia (but not isolated hypercholesterolemia) has been reported in $75 \%$ to $80 \%$ of gouty patients, ${ }^{33}$ and is only partially explained by obesity and ethanol consumption. Hypertension may also be a risk factor for hyperuricemia. Hyperuricemia occurs in $22 \%$ to $38 \%$ of hypertensive patients before treatment and the prevalence is further increased by diuretic use.

While type 2 diabetes is a known risk factor for metabolic syndrome and for gout, it appears that those with a higher degree of insulin resistance are more at risk. ${ }^{34}$ Some of the recognized risk factors for hyperuricemia are given in Tables 1 and 2.

Cyclosporine is a major factor in the surprisingly high prevalence of gout among heart transplant patients, as high as $24 \%$ in one study. ${ }^{51-53}$

One of the most recent and fascinating developments in the understanding of risk factors for gout is the hypothesis that there is a strong correlation between consumption of fructose and development of both metabolic syndrome and hyperuricemia. ${ }^{50,54}$ Rats fed a high-fructose diet develop hyperuricemia, hypertension and afferent arteriopathy that are ameliorated (including improvement in histomorphology) by allopurinol, febuxostat or benzbromarone, and there is accumulating evidence in humans. ${ }^{55,56}$ On the other hand, the view that current levels of fructose intake are reasonably safe is eloquently argued by White. ${ }^{57,58}$

The safety of high fructose corn syrup (HFCS) was never seriously questioned until recently because the composition is very similar to that of sucrose, except for the presence of the disaccharide bond in sucrose. ${ }^{58}$ HFCS contains sugars mainly in the form of monosaccharides. The most commonly used high fructose products are HFCS-42 and HFCS-55, which
Table I Some recognized risk factors for hyperuricemia

Purine over-ingestion'

Metabolic syndrome

Ethanol use ${ }^{35}$

Renal insufficiency

Filipino ancestry ${ }^{36}$

Psoriasis $^{37}$

Myeloproliferative ${ }^{38}$ and lymphoproliferative ${ }^{39}$ disorders

Chronic lead poisoning ${ }^{40}$

Dehydration

The postoperative state ${ }^{41}$

Critical illness with metabolic acidosis ${ }^{42}$

Sarcoidosis ${ }^{43}$

Hyperparathyroidism ${ }^{44}$

Ketosis $^{45}$

Polycystic kidney disease ${ }^{46}$

Down syndrome ${ }^{47}$

Hypoxanthine-guanine phosphoribosyl-transferase deficiency

(Lesch-Nyhan syndrome when homozygous) ${ }^{48}$

Phosphoribosylpyrophosphate synthetase overactivity ${ }^{49}$

Glucose-6-phosphatase deficiency (von Gierke's disease) ${ }^{49}$

Fructose I-phosphate aldolase deficiency ${ }^{50}$

contain $42 \%$ and $55 \%$ fructose, respectively, with the balance of the carbohydrates consisting mainly of glucose. Sucrose is a disaccharide consisting of equal parts (50\% each) of fructose and glucose. The term "high fructose corn syrup" is used to distinguish it from simple corn syrup which contains carbohydrate almost exclusively in the form of glucose.

How would excessive fructose intake cause hypertension? As intriguingly detailed by Soleimani, ${ }^{59}$ increased dietary fructose stimulates both salt and fructose absorption from the small intestine, but also reabsorption of sodium in the kidney proximal tubule. This is thought to be due to the presence of the same fructose-stimulated transporter mechanisms in both locations. In animal experiments, fructose-induced hypertension could be abrogated by feeding a low-salt diet. Soleimani

Table 2 Drugs associated with hyperuricemia

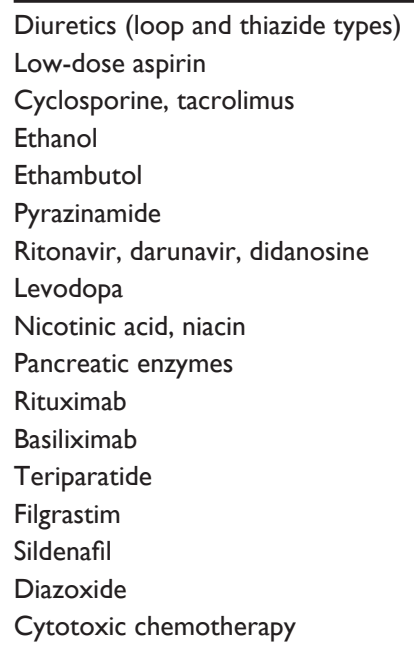


argues that increased dietary fructose and salt are additive in their effects, and optimal blood pressure control for the hypertensive population would require reduction of both nutrients.

Does fructose cause hyperuricemia in humans as it does in animals? Prospective data are difficult to find. Akhavan and colleagues administered $300 \mathrm{kcal}$ sugar loads to normal subjects. The sugar loads consisted of different ratios of glucose to fructose $(\mathrm{G} / \mathrm{F})$. Sucrose was also used. A sugar load consisting of $20 \%$ glucose and $80 \%$ fructose is designated as G20/F80. Uric acid levels began to rise within 15 minutes after the sugar loads. By 45 minutes, uric acid level rose by $\sim 61 \mu \mathrm{mol} / \mathrm{L}$ $(\sim 1.02 \mathrm{mg} / \mathrm{dL})$ in the G20/F80 group, but only approximately half that in the sucrose group and in the G50/F50 group, although the difference was not statistically significant, perhaps because of the small sample size $(n=7)$. Baseline mean uric acid level in this study was $295.9 \mu \mathrm{mol} / \mathrm{L}(\sim 5.0 \mathrm{mg} / \mathrm{dL}) .{ }^{60}$ Nevertheless, definitive prospective data indicating that longterm fructose overconsumption contributes to long-term hyperuricemia in human populations are still lacking.

Is renal insufficiency of any cause a risk factor for gout? This has been a controversial question. Because of the complex handling of uric acid by the kidney (see Pathophysiology below), it seems to depend on the cause of the renal insufficiency. The incidence of kidney stones is markedly reduced in many cases of renal insufficiency. ${ }^{61}$ Diseases that are primarily glomerular do not seem to increase the incidence of gout until glomerular filtration rate (GFR) falls to $\sim 15 \mathrm{~mL} / \mathrm{min}$ because of a compensatory increase in tubular secretion resulting in a markedly increased fractional excretion of uric acid. ${ }^{61,62}$ Tubular diseases, on the other hand, can either increase or decrease the incidence of gout depending on which part of the tubule is affected. Other factors that may contribute to the relatively low rate of hyperuricemia and gout in patients with chronic kidney disease $(\mathrm{CKD})$ include lower protein intake and increased intestinal clearance of uric acid. As with gouty patients with normal renal function, most patients with CKD and gout are "underexcretors" of uric acid for their level of serum creatinine. ${ }^{62}$ The question as to whether CKD is a risk factor for hyperuricemia was recently reviewed by Feig who looked at 11 studies published in the past several years. He noted that 7 studies supported such an association while 4 did not. ${ }^{63}$

\section{Role of uric acid in cardiovascular and renal disease}

In addition to epidemiologic studies that have consistently indicated that hyperuricemia itself is a risk factor for cardiovascular disease rather than an innocent bystander, additional lines of experimental evidence now support this notion. There is evidence that uric acid itself may contribute to vascular endothelial dysfunction and plays a "pro-oxidant" role. While the exact mechanisms are not known, experimental hyperuricemia in rats produced hypertension, endothelial dysfunction, interstitial disease and vascular smooth muscle proliferation. ${ }^{64-67}$

In 1982, Gibson and colleagues demonstrated that allopurinol treatment of a group of gouty patients with CKD resulted in preservation of GFR, in contrast to a control group. ${ }^{68}$ Avram and Krishnan recently reviewed clinical studies of hyperuricemia and CKD, and concluded that most studies show hyperuricemia to be an independent risk factor for the future development of CKD. ${ }^{69} \mathrm{Siu}$ and colleagues published a small controlled trial that showed a trend toward preservation of GFR using allopurinol in hyperuricemic patients with mild to moderate CKD. ${ }^{56} \mathrm{~A}$ recently presented abstract found that long-term febuxostat improved or preserved GFR in gouty patients. ${ }^{70}$

There have been several critical reviews of the evidence linking hyperuricemia in a causative role with cardiovascular disease, with the conclusion being that the association seems reasonably strong, but is not yet definitive. ${ }^{71,72}$

Does hyperuricemia directly cause hypertension? Perhaps the most compelling evidence comes from animal studies in which induced hyperuricemia causes hypertension that is reversible with hypouricemic agents including febuxostat, allopurinol and benzbromarone. ${ }^{73}$ In one such study, experimental hyperuricemia using oxonic acid (an inhibitor of uricase) also caused glomerular hypertrophy, afferent arteriolar sclerosis and macrophage infiltration. ${ }^{74}$

Prospective data in humans that definitively establish causality between hyperuricemia and hypertension are lacking. Nevertheless, a number of such studies suggest a causal relationship without another likely explanation. ${ }^{75-78}$ One large epidemiologic study using a subset of the Multiple Risk Factor Intervention Trial (MRFIT) database followed for 6 years men who had hyperuricemia (serum uric acid $>7.0 \mathrm{mg} / \mathrm{dL}$ ) but without either hypertension or metabolic syndrome. The presence of hyperuricemia alone increased the risk of developing hypertension by $80 \%$ after control for other known risk factors. ${ }^{79}$ Epidemiological studies in children and adolescents have strongly associated hyperuricemia with the later development of hypertension, but perhaps most interesting is a prospective study that used allopurinol in adolescents to successfully treat hypertension. ${ }^{80}$ Results have been inconsistent in adults. It has therefore been hypothesized that the 
pathophysiology of essential hypertension is still reversible in adolescents but becomes fixed by adulthood.

If hyperuricemia causes hypertension and cardiovascular disease, what is the mechanism? There may be several. The role of fructose has recently been highlighted as discussed above. Vascular reactivity (itself a part of the metabolic syndrome) has also been reported as a direct effect of hyperuricemia. For instance, using isolated rat aorta rings, Nakagawa and colleagues demonstrated a striking relationship between uric acid level and impaired vasorelaxation in response to acetylcholine perfusion. ${ }^{50}$ This effect was apparent even at physiologic concentrations of uric acid for the rat $(\sim 1.5 \mathrm{mg} / \mathrm{dL})$. Data are less direct in humans. One study found serum uric acid to be an independent risk factor for forearm blood flow in patients on stable peritoneal dialysis. ${ }^{81}$

Gout has long been associated with congestive heart failure, with the presumed association simply being hyperuricemia due to diuretic use, but recent research suggests that uric acid level in itself is associated with diastolic dysfunction and left ventricular hypertrophy (independent of any effect on blood pressure), and is an independent risk factor for congestive heart failure. ${ }^{82,83}$

Pre-eclampsia is associated with hyperuricemia, higher serum levels being associated with worse intrauterine growth retardation. Recent research suggests that elevated uric acid plays a role in impaired amino acid transport through the placenta, and may thus play a causative role. ${ }^{84}$

\section{Pathophysiology Renal handling of urate}

There have been a number of advances in the understanding of the renal handling of uric acid in recent years. ${ }^{85}$ First, it is important to realize that the upper limit of normal for serum uric acid (approximately $8.0 \mathrm{mg} / \mathrm{dL}$ for men in most labs) is not at all related to the solubility of uric acid in serum, but is derived purely from population-based studies of "normal" persons. The upper limit of uric acid solubility in serum at physiologic $\mathrm{pH}$ and temperature is approximately $6.8 \mathrm{mg} / \mathrm{dL}$. This level is much more relevant for gout. The normal body urate pool in men ranges from about 800 to $1500 \mathrm{mg}$ with a daily turnover of approximately two-thirds. ${ }^{86}$ The body pool of urate is expanded in gouty patients, both because of hyperuricemia and also because of deposition of monosodium urate (MSU) in tissues (which may be asymptomatic for many years).

Most ( $85 \%$ to $90 \%)$ of gouty patients are defined as "underexcretors". ${ }^{87}$ In this group, measurements of endogenous uric acid production is normal, so it is assumed that the kidney is not excreting enough uric acid to maintain serum levels in the normal range $(<6.8 \mathrm{mg} / \mathrm{dL})$. It could also be said that the kidney excretes normal amounts of uric acid only when the serum level is elevated.

Uric acid is freely filterable at the glomerulus. Almost all of the filtered uric acid is then reabsorbed in the $\mathrm{S} 1$ segment of the proximal tubule. Of the reabsorbed urate, $45 \%$ to $50 \%$ is then secreted in the S1 and S2 segments of the proximal tubule. Much of the secreted urate is again reabsorbed in the S3 segment of the proximal tubule. ${ }^{85}$ Most persons who are hyperuricemic never get gout, but the risk of gout goes up dramatically with higher serum uric acid levels. In one large study, the 5-year risk of gout varied from $0.6 \%$ for those with a serum uric acid level of $<7 \mathrm{mg} / \mathrm{dL}$ to $30.5 \%$ for those with a level of $10 \mathrm{mg} / \mathrm{dL}$ or higher. ${ }^{28}$

In recent years a family of organic anion transporter proteins has been discovered. Enomoto and colleagues cloned one called urate transporter 1 (URAT-1) which is highly specific for urate transport. ${ }^{88}$ URAT- 1 is present in the proximal tubular epithelial cells ${ }^{89}$ and exchanges urate with other endogenous organic anions as well as drug anions. Most uricosuric drugs are thought to act by suppressing the activity of URAT-1, including probenecid, benzbromarone, sulfinpyrazone and losartan. In the case of probenecid at least, there may also be an ATP-inhibiting effect via pannexin-1. ${ }^{90}$ Aspirin may also affect uric acid excretion in part through a mechanism involving URAT-1. URAT-1 is thought to be critically important in maintaining serum uric acid levels. Individuals with nonfunctional mutations of URAT-1 have very low uric acid levels. ${ }^{89,91}$ The clinically relevant biology of URAT-1 has recently been reviewed. ${ }^{92}$

UAT-1 is another renal urate transporter that has subsequently been identified as galectin- $9 .{ }^{93}$ Its role in intestinal and renal secretion of urate anion has yet to be established. A number of other urate transporters have been discovered, and seem especially important in hereditary gout. ${ }^{94-97}$

Patients with familial juvenile hyperuricemic nephropathy (FJHN) have early onset of hyperuricemia, hypertension, progressive renal failure and variable degrees of gout. Most cases are due to a mutation in the UMOD gene which encodes uromodulin (Tamm-Horsfall glycoprotein). ${ }^{85,98}$ Uromodulin is hypothesized to be important for the structural integrity of the ascending loop of Henle. Although phenotypically distinct from FJHN, some forms of medullary cystic kidney disease, type 2 and glomerulocystic kidney disease are also thought to be attributable to mutations in UMOD and have hyperuricemia associated with them..$^{85,99}$ 


\section{Inflammation in gout - recent discoveries}

The discovery of elevated serum uric acid levels in gouty patients is normally credited to Garrod in $1859 .{ }^{100}$ It was not until 1962 that the inflammatory nature of MSU, the insoluble, crystalline salt of uric acid that typically forms tophi, was proven. In that year Faires and McCarty injected their own knees (and those of their fellows) with MSU, proving that minute quantities of crystals can cause severe inflammation. ${ }^{101}$ Yet, it is well known that between attacks in up to $70 \%$ of gouty patients, MSU crystals can be found floating free in synovial fluid without inciting inflammation. ${ }^{102}$ Clearly other factors besides the simple presence of crystals are at work to turn on/off the inflammatory cascade.

\section{Triggering of inflammation by crystals}

The predilection of gout for the first metatarsophalangeal joint (MTP) has been hypothesized to represent the result of a number of factors. ${ }^{103}$ It is hypothesized that a small joint effusion forms during daytime activities, particularly activities that are more strenuous or traumatic to the joint (the first MTP is a frequent site of minor trauma and hence, osteoarthritis). At night (when most gout attacks occur) tissue edema fluid (more abundant more distally in the lower extremity) is gradually reabsorbed into the circulation. The concentration of urate rises in the joint because urate is reabsorbed more slowly than water. The lower temperature of the distal foot is thought to also contribute to precipitation of MSU crystals. The net result is the classic but unwelcome nocturnal visitor that so rudely awakens the victim from a sound sleep.

For a gout attack to occur, there must be deposition of MSU in the tissues and there must also be the triggering of inflammation. Crystals alone are not enough, as evidenced by the fact that tophi only occasionally become inflamed, and also that MSU crystals can often be found floating freely in synovial fluid from uninflamed joints. A number of factors have been discovered in recent years that control the inflammatory process, and there are several eloquent reviews. ${ }^{1,85,104-108}$

Liberation of free crystals is one factor that can trigger the acute gout attack. Free crystals can be newly deposited, or may form through dissolution of tophi (as when instituting treatment with a hypouricemic agent) or may be dislodged from otherwise stable deposits by trauma. ${ }^{109}$ It is estimated that only approximately $20 \%$ of persons with sustained hyperuricemia actually develop gout. ${ }^{28} \mathrm{~A}$ rapid decline in serum uric acid level can precipitate an attack. This often occurs at the start of hypouricemic therapy or more characteristically when an alcoholic suddenly ceases to imbibe ethanol for any reason.

Although not as novel as the developments reported in the following, protein-coating of crystals has been shown in the past to affect inflammation. Coating with IgG, complement fragments or fibronectin are pro-inflammatory in this regard, while coating with lipoproteins $\mathrm{B}$ and $\mathrm{E}$ reduces the inflammatory reaction to the crystals..$^{108,110,111}$

\section{Cytokines}

Much remains to be learned about the process of crystalinduced inflammation, but there have been some advances in recent years, and there are several recent reviews. ${ }^{108,112}$ Crystals of MSU or calcium pyrophosphate dihydrate (CPPD) trigger intense neutrophilic influx into joints in just 1 to 2 hours. ${ }^{101,113}$ In addition to neutrophils, other cell types are also capable of phagocytizing crystals including monocytes and endothelial cells. ${ }^{114-116}$ Recent studies by Martin and colleagues suggest that resident macrophages (rather than recruited neutrophils and monocytes) actually initiate and drive the inflammatory response, ${ }^{117,118}$ while eventual differentiation of monocytes into macrophages results in resolution of crystal-induced inflammation.

Research over the past 20 years has demonstrated central roles for the cytokines IL-1 $\beta$, IL- 6 , tumor necrosis factor- $\alpha$ (TNF- $\alpha$ ) and IL-8. ${ }^{118}$ IL-1 seems to be particularly important since IL-1 inhibitors can abort crystal-induced inflammation both in vitro and in the clinic.

As reviewed by Liu-Bryan and Rose, ${ }^{108}$ neutrophils move into joints by the actions of IL- 1 and TNF- $\alpha .{ }^{104,119}$ This stimulates upregulation of E-selectin and chemotactic factors CXCL8 and CXCR2. Phagocytosis of crystals by neutrophils then causes release of cytoplasmic mediators such as calgranulins. ${ }^{120}$

MSU crystals can activate several inflammatory pathways directly. MSU crystals are rapidly phagocytized by neutrophils in vitro and in vivo. They stimulate monocytes to express large quantities of IL-1 $\beta$ (via formation of the NALP-3 inflammasome complexes). ${ }^{104,121,122}$ Uric acid has been included among the "endogenous alarmins". ${ }^{123}$

One of the primary mediators of urate-induced inflammation is IL- $1 \beta .{ }^{124,125}$ Interestingly, IL- $1 \beta$ production by mononuclear cells is triggered by MSU but not by CPPD or hydroxyapatite, ${ }^{124,126}$ suggesting that crystal-induced inflammation can be triggered by other pathways as well. Nevertheless, the formation of IL-1 is a clinically important process that can be blocked by IL-1 inhibitors to great therapeutic advantage.

\section{Inflammasomes}

The term "inflammasome" first appeared in the medical literature in 2002. ${ }^{127}$ Martinon and colleagues described it as a caspase-activating complex that includes caspase-1, caspase-5, Pycard/Asc, and NALP1, a pyrin domain-containing protein 
sharing structural homology with NODs (NALP = NACHT domain, leucine-rich repeat domain, and pyrin domain).

Inflammasomes are large intracellular assemblies of several types of proteins that trigger or facilitate the inflammatory process. ${ }^{122,128,129}$ Inflammasomes are an important intracellular mediator in the production of IL-1 $\beta$ and IL-18 and may also induce cellular pyroptosis, a type of programmed cell death distinct from apoptosis. ${ }^{130} \mathrm{IL}-1 \beta$ is activated by intracellular cleavage of Pro-IL-1 by caspase-1. Caspase-1 in turn is thought to be activated by the NALP-3 inflammasome. Mutations in the NALP-3 inflammasome may lead to IL-1 $\beta$ overproduction, as in familial Mediterranean fever. There have been several thorough reviews on the role of inflammasomes in gout and in other auto-inflammatory conditions, particularly the cryopyrinopathies such as familial coldinduced urticaria, Muckle-Wells syndrome and CINCA syndrome (chronic infantile neurologic, cutaneous, articular syndrome). ${ }^{122,131-134}$

\section{Toll-like receptors}

Toll-like receptors (TLRs) are membrane-bound extracellular receptors that constitute an important part of the innate immune system. Their primary function is to recognize microbial invaders. ${ }^{122}$ NOD-like receptors are intracellular complexes that sense microbial and nonmicrobial danger signals (such as crystals) and then form inflammasomes.

There is some understanding of how IL-1 production is triggered. The innate immune system in the form of TLRs appears to be involved, ${ }^{119,135-137}$ especially TLR-2 and TLR-4 which have been shown to be activated by MSU crystals. ${ }^{104,135}$ Using a mouse model and protein-free, endotoxin-free MSU crystals, it was found that deficiency of TLR-2 and/or TLR-4 resulted in blunted production IL-1 $\beta$, TNF- $\alpha$ and other cytokines. ${ }^{119}$ While TLRs appear to have a role in the amplification of the inflammatory response, there is also some evidence from murine models that they are not actually required. ${ }^{118}$

CD14 is a pattern recognition receptor on the surface of phagocytic cells that seems to be important for crystal-induced IL-1 production. Scott and colleagues found that MSU crystals but not latex beads, diamond crystals or aluminum triggered CD14 activation. CD14 deficient cells were still able to phagocytize crystals but expressed approximately $90 \%$ less IL- $1 .{ }^{137}$ There is some evidence from murine models that TLRs do not bind MSU directly, but rather that CD14 binds to the crystals, making the crystals recognizable by TLRs. ${ }^{118,137}$

\section{Resolution of the gout attack}

Gout attacks eventually resolve, even without specific treatment. If little is known about how crystals initiate inflammation, less is known about the mechanisms leading to spontaneous resolution of gout. As monocytes differentiate into macrophages they appear to lose the ability to secrete inflammatory cytokines in response to MSU crystals. Yagnik and colleagues recently showed that such differentiated macrophages also secrete anti-inflammatory cytokines, particularly TGF- $\beta 1 .{ }^{138}$ Other anti-inflammatory mediators such as IL-10, PGD2 and 15deoxy-PGJ2 (ligand of PPAR $\gamma$ ) are also secreted mainly by macrophages. ${ }^{108,138,139}$

Resolution of gout follows the normal 3-phase pattern found in the body, including removal and/or neutralization of crystals, clearance of apoptotic cells and debris, and a switch of cytokine patterns from the pro-inflammatory to anti-inflammatory. ${ }^{108}$ Superoxide seems to help break down MSU crystals but not CPPD crystals. ${ }^{140}$

Although it is often said that crystals (mostly extracellular but occasionally intracellular as well) may be found in joints between attacks, it is important to realize that low-level inflammation persists along with the potential for ongoing joint damage. ${ }^{141}$

\section{Notes on clinical gout}

Nearly every physician is familiar with the acute, nocturnal, monoarticular presentation of gout in the first MTP joint that awakens the sufferer from sound sleep. Some notes on the less common clinical features of gout may be helpful. There are 4 stages in the development of clinical gout: ${ }^{142}$ asymptomatic hyperuricemia, the gouty attack (usually monoarticular, at least at first), the intercritical period and chronic gouty arthritis. In most persons, hyperuricemia exists for many years before the first clinical attack of gout. While the first clinical attack is usually monoarticular, it could also be polyarticular. The first MTP joint is the first joint attacked in roughly $50 \%$ of individuals. Some persons never have clinical attacks of gout, but rather they slowly build tophaceous deposits in and around joints. One characteristic presentation is acute inflammation of 1 or more finger joints, particularly Heberden's nodes in elderly females with osteoarthritis who are using diuretics. ${ }^{143,144}$

Attacks before the age of 25 to 30 years in men (or at any time any premenopausal woman) should raise the suspicion of an inborn enzyme defect or one of several hereditary kidney diseases. The latter include familial juvenile hyperuricemic nephropathy, autosomal dominant medullary cystic kidney disease and autosomal dominant polycystic kidney disease. ${ }^{46}$

Pain is the last symptom to appear and the first to disappear. A corollary of this is that relatively painless swelling of a joint or a digit may persist for weeks. This often gives 
rise to a fear of osteomyelitis, occasionally resulting in unnecessary surgery to debride an "infected" digit. Gout is a common cause of dactylitis in adults. Other common causes include psoriatic arthritis, sarcoidosis, osteomyelitis and, in children, sickle-cell disease. The affected digit may even take on a dusky, reddish purple hue as the inflammation becomes chronic. If the attack persists untreated, and if inflammation has been severe, desquamation tends to occur. Dactylitis can take 1 or 2 months to resolve. ${ }^{142}$

Unfortunately, attacks tend to become more frequent and more severe with time with a tendency to involve more joints.

The intercritical period begins after resolution of the first gout attack. During this stage, joints appear to return to normal. During this stage, ultrasound or magnetic resonance imaging (MRI) may still show tophaceous deposits around affected joints. Untreated, such deposits tend to worsen with time.

The stage of chronic tophaceous gout occurs when monosodium urate builds up around tissues so as to be clinically obvious between attacks. The word "tophus" is derived from the Greek word for chalk. Tophi may be quite firm and may be confused with tumors. Tophi mimic rheumatoid nodules, particularly in men where they tend to occur along the olecranon aspect of the forearm. Tophi can form over an interval of only a few days in persons with severe hyperuricemia, such as occurs with critical illness hyperuricemia. ${ }^{142,145}$ Occasionally, spontaneous rupture occurs. The white, pasty material that exudes is almost pure MSU, sometimes with ultramicroscopic calcium crystals, but only rarely white cells. Untreated, draining tophi can take months or years to close. Detailed descriptions of the osseous and the dermatologic manifestations of gout have been published. ${ }^{142}$

Tophaceous material is a white pasty substance that is easily identified microscopically as sheets of needle-shaped crystals. MSU crystals are somewhat soluble in water and formaldehyde. Pure alcohol fixation is necessary to preserve the crystals in tissue samples. ${ }^{146,147}$

\section{Role of diagnostic imaging}

Definitive diagnosis of gout (including differentiation from pseudogout and the ever-lurking specter of septic arthritis) has traditionally required arthrocentesis. Until recently, imaging has not been particularly helpful. The subject of imaging has been recently reviewed. ${ }^{148,149}$

Traditional radiographs are largely unhelpful in the diagnosis of gout since the crystals are relatively radiolucent, and bony changes do not occur until late in the course of the disease. Radiographs are helpful to look for chondrocalcinosis which would lead to a diagnosis of pseudogout instead. Late destructive changes of gout that may be apparent on radiographs include overhanging edges, erosions and cysts within bone. The presence of overhanging edges helps distinguish gout from rheumatoid arthritis. Also helpful is the tendency of bony erosions and cysts in gout to have sclerotic margins, and there is usually absence of joint space narrowing and there is lack of periarticular demineralization.

Imaging of gout in the US took a leap forward in the past 10 years with the popularization of musculoskeletal ultrasound, which has been used for many years in Europe. ${ }^{150}$ Ultrasound offers the ability to diagnose gout between attacks (when there is little or no aspiratable fluid in joints) or in patients who may have asymptomatic hyperuricemia. Ultrasound may also allow diagnosis of palpable tophaceous deposits without needle aspiration, and may allow differentiation between gout and pseudogout based on the location and characteristics of the crystal deposits. ${ }^{151}$ Gouty joints often show the characteristic "double contour sign" on ultrasonographic imaging. ${ }^{152}$ We find ultrasound to be particularly helpful in the long-term management of gout by following the dissolution of tophaceous deposits over time and using this information to adjust the intensity of hypouricemic treatment.

The main drawback of ultrasound is the need for somewhat extensive training and practice. It is also not yet universally available in the US. Most radiologists and rheumatologists in the US do not receive significant training in the musculoskeletal application of ultrasound.

Magnetic resonance imaging and computed tomography have also been used to diagnose gout, particularly tophaceous deposits. MRI is particularly helpful in detecting bony changes that are not visible on plain radiographs. ${ }^{153,154}$ One caveat is that the magnetic resonance appearance may mimic osteomyelitis particularly during the acute attack when there may be intraosseous edema and also soft tissue inflammation. We have seen 2 patients operated for lumbar osteomyelitis who in reality had acute gout of the facet joints that improved rapidly with corticosteroid treatment.

\section{Treatment of the acute attack}

The treatment of gout is traditionally divided into 3 phases: 1) treatment of the acute attack; 2) prevention of future attacks; and 3) hypouricemic therapy. We will consider each separately.

Inappropriate treatment of acute gout seems to persist. One recent study found that of 159 patients who consulted a physician for their gout, 10 received definitely inappropriate treatment and 43 received potentially inappropriate treatment 
for their recurrent attacks. Inappropriate treatment was defined as use of a hypouricemic agent to treat an acute attack, without having used it prophylactically previously. ${ }^{155}$

\section{Nonsteroidal anti-inflammatory agents}

Nonsteroidal anti-inflammatory drugs (NSAIDs) are the drugs of choice for the average patient with gout without comorbidities. They are usually not an option in persons with chronic renal disease as they can worsen renal function temporarily or permanently, cause fluid retention and increase blood pressure, occasionally dramatically. This holds true to both traditional NSAIDS such as indomethacin as well as COX-2 inhibitors such as celecoxib, although the latter seems to be much more benign in this regard than the related drug rofecoxib, which was withdrawn from the market in the US.

\section{Colchicine}

Colchicine is perceived as safer than NSAIDs in patients with mild to moderate renal insufficiency, as long as the maintenance dose is adjusted. Colchicine is an alkaloid derived from Colchicum autumnale, the autumn crocus, a species that is more properly placed in the lily family. Plant extracts containing colchicine have been used to treat gout for more than 2000 years. The oral form of colchicine has been available for gout treatment for 70 years. However there has been no FDA-approved preparation until recently and the branded product is being marketed under the name of Colcrys $^{\circledR}$; URL Pharma, Inc.).

The Colcrys ${ }^{\circledR}$ trial showed that a low-dose regimen of colchicine ( $1.8 \mathrm{mg}$ total over 1 hour) and a high-dose regimen ( $4.8 \mathrm{mg}$ total over 6 hours) were equivalent in aborting the acute gout attack at 24 hours, with many fewer adverse events in the low-dose group. Additionally, formal recommendations for using colchicine in patients with renal insufficiency and hepatic insufficiency were made, and the many drug interactions of colchicine were formalized. ${ }^{156}$

Colchicine is a drug with both a narrow therapeutictoxicity window and a marked variability between individuals in drug disposition. Often, the cumulative dose that relieves the gout attack is close to the dose that causes diarrhea, abdominal cramping and nausea. Dose reduction is commonly recommended in patients with a creatinine clearance of less than $50 \mathrm{~mL} / \mathrm{min}$. Because the Colcrys ${ }^{\circledR}$ regimen is itself lowdose, dosage adjustment is not necessary in the presence of mild-to-moderate renal insufficiency, according to the official prescribing information. ${ }^{157}$ In severe renal insufficiency, the dosing for acute flares is unchanged $(1.8 \mathrm{mg} / 24$ hours $)$ but it should not be repeated more frequently than every 2 weeks.
The prophylactic dose should be reduced to $0.3 \mathrm{mg} /$ day. In patients receiving dialysis, the dose for gout flares is reduced to $0.6 \mathrm{mg} \times 1$ dose only, to be repeated in not less than 2 weeks. The prophylactic dose is reduced to $0.3 \mathrm{mg}$ twice a week "with close monitoring". ${ }^{157}$ Colchicine is not removed by dialysis or exchange transfusion. ${ }^{158}$ The manufacturer does state that Colcrys ${ }^{\circledR}$ is contraindicated in patients with severe renal impairment who are also receiving drugs that inhibit permeability glycoprotein (P-glycoprotein, P-gp; also known as $\mathrm{ABCB} 1$ ) or that inhibit CYP3A4. P-gp is an important transporter protein in the elimination of colchicine.

Colchicine undergoes metabolism by the liver primarily through deacetylation. Approximately $20 \%$ of the parent drug is excreted unchanged in the urine; in the face of hepatic dysfunction, this percentage increases.

Serious colchicine toxicity includes severe diarrhea leading to dehydration and metabolic acidosis, bone marrow failure, polyneuropathy, chronic myopathy and rhabdomyolysis. Risk factors for toxicity include older age, concomitant use of CYP3A4 inhibitors (such as cimetidine, erythromycin, clarithromycin, diltiazem, verapamil, and HMG-CoA reductase inhibitors), inhibitors of P-gp (such as cyclosporine), and most consistently, renal impairment.

Cyclosporine potentiates colchicine neuromyopathy as does renal insufficiency which itself may be induced by cyclosporine, compounding the problem. Neuromyopathy may occur within weeks of starting the combination. Notably, cyclosporine delayed colchicine-induced diarrhea in an animal model system, likely due to modulation of intestinal P-gp. ${ }^{159}$ Hence, it is suspected that cyclosporine could mask the gastrointestinal side effects of colchicine that customarily signal the onset of acute toxicity. Myopathy and neuropathy are often reversible upon discontinuation of the medication within 2 to 12 weeks. ${ }^{160,161}$

In 2008 the FDA withdrew marketing approval for all existing intravenous preparations of colchicine secondary to inappropriate use and high mortality associated with its use.

\section{Intra-articular and systemic corticosteroids}

Intra-articular corticosteroids are particularly helpful in acute gout. Injected joints are usually markedly improved in 24 hours. In our experience, intra-articular corticosteroids provide the fastest resolution of the acute gouty flare. Intraarticular steroids are also very safe in patients with renal insufficiency and should perhaps be a treatment of first choice unless there is polyarticular gout. When properly performed, arthrocentesis should not be particularly uncomfortable, 
even with an inflamed joint. Lack of operator experience is probably the main impediment to more widespread use of intra-articular corticosteroids.

Intra-articular corticosteroids may not be feasible when many joints are affected. Systemic corticosteroids are a better option in such cases. Prednisone in a dose of $30 \mathrm{mg}$ twice daily is effective in most cases. Because of the short half-life of prednisone, once daily dosing is often ineffective. Oral corticosteroids are well absorbed and are generally as effective as intravenous steroids. Corticosteroids are tapered over 7 to 10 days. It is important to begin a prophylactic agent such as colchicine when tapering corticosteroids to avoid a rebound flare of gout activity.

\section{Biologicals}

There is some anecdotal evidence for the effectiveness of TNF- $\alpha$ blocking agents for the management of severe gout. ${ }^{162,163}$ Conceptually this makes some sense, since crystals are a potent stimulus for TNF- $\alpha$ production by mononuclear cells. ${ }^{164,165}$ Controlled trials in gouty subjects are lacking to date.

In one report the IL-1 receptor antagonist anakinra (Kineret $^{\circledR}$; Biovitrum AB) was reported to be rapidly effective in suppressing flares in 10 patients with difficult-to-treat acute gout. ${ }^{166}$ Anecdotally, inhibition of IL-1 may be a more effective strategy for treating acute gout than inhibition of TNF- $\alpha{ }^{167,168}$ There are some patients with severe gouty flares who cannot or should not receive NSAIDs, colchicine or highdose corticosteroids, or who are refractory to such treatments. In such cases, anakinra is sometimes an alternative although it is not FDA-approved for treatment of gout. While expensive if used chronically for rheumatoid arthritis (for which the drug is approved), at a cost of US\$75 per day it is actually quite costeffective when given for 3 to 5 days to hospitalized patients who otherwise might require high-dose intravenous corticosteroids with treatment of resulting steroid complications.

\section{On the horizon}

Rilonacept (Arcalyst ${ }^{\circledR}$; Regeneron Pharmaceuticals, Inc.) is a dimeric fusion protein that acts as an IL-1 inhibitor that is FDA-approved for treatment of cryopyrin-associated periodic fever syndromes. Its effectiveness in chronic tophaceous gout was assessed in a pilot study. While it did not reduce the number of affected joints, it did decrease the severity of symptoms in affected joints. It also decreased C-reactive protein (CRP) levels initially but CRP trended upward as treatment continued beyond 6 weeks. ${ }^{169}$

Canakinumab is an investigational fully humanized monoclonal antibody directed against IL-1 $\beta$. In a Phase II study involving 191 subjects with acute, difficult-to-treat gout, single doses of canakinumab were more effective beginning at 24 hours than triamcinolone acetonide $40 \mathrm{mg}$ intramuscularly. It also effectively prevented recurrences for up to 8 weeks. ${ }^{170}$ Canakinumab (Ilaris ${ }^{\circledR}$; Novartis Pharmaceuticals) is currently FDA-approved and available on the US market for treatment of cryopyrin-associated periodic fever syndromes including familial cold autoinflammatory syndrome and Muckle-Wells syndrome.

Biological treatment/prophylaxis of gout attacks is still in its infancy. There are many questions to be addressed before biological treatment can be generally recommended. Among the issues to be resolved are the very high cost, as yet unproven efficacy and unclear safety profile compared with traditional agents.

Tranilast is an interesting investigational compound (it is on the market in parts of Asia) with anti-inflammatory, antifibrotic and uricosuric effects. It is currently in trials for gout, hyperuricemia and other conditions. It has the potential to act as both a suppressor of acute attacks and possibly a hypouricemic therapy as well. ${ }^{171}$

Apremilast is a novel phosphodiesterase 4 (PDE 4) inhibitor with potent anti-inflammatory properties which is currently being studied as a treatment for acute gout attacks. ${ }^{172,173}$ As with tranilast, it has the potential to prevent acute flares in those who may not be able to use NSAIDs.

\section{Attack prophylaxis}

Once the acute attack has subsided, the next goal is prevention of future attacks. ${ }^{142}$ This is particularly important in the first few weeks after an acute attack. Generally, either an NSAID or colchicine is used for this purpose. NSAIDs are the treatment of choice in persons with concomitant osteoarthritis. For prophylaxis, lower doses usually suffice, such as celecoxib $200 \mathrm{mg}$ daily or naproxen $375 \mathrm{mg} /$ day. Indomethacin is not recommended for this use, particularly in persons who are taking triamterene, in whom it can cause acute renal failure. ${ }^{174,175}$ Colchicine prophylaxis is used in persons who cannot or should not take NSAIDs. As described above, the dose of colchicine must be reduced in the presence of renal or hepatic insufficiency. Chronic colchicine toxicity takes the form not of diarrhea, but rather of myoneuropathy which combines symptoms of peripheral neuropathy with muscle weakness and usually mildly elevated creatine kinase. ${ }^{161,176-178}$ Unfortunately, a few individuals cannot take even $0.3 \mathrm{mg} /$ day of colchicine without severe diarrhea. This appears to be idiosyncratic. Prophylaxis remains a major problem in these individuals. Rarely, we have used low-dose 
daily corticosteroid treatment as a preventive when there has been no other choice, but our impression is that tachyphylaxis develops fairly rapidly to the preventive effect and dosage escalation is required, with all of the attendant side effects and risks that accompany chronic corticosteroid use. IL-1 inhibitors offer an effective if expensive alternative. As noted above, 2 such agents are currently available on the US market but are not FDA-approved for use in gout.

The duration of prophylaxis varies. In a person without obvious tophaceous deposits who has only occasional attacks, prophylaxis may be necessary for only 2 or 3 weeks. Prophylaxis is generally used for several months in those who are also beginning a hypouricemic agent, because more frequent attacks may accompany sudden lowering of uric acid levels. ${ }^{142,179}$ Generally, the more potent the hypouricemic effect, the more frequent and the more severe are the gout flares during the initial months of hypouricemic treatment. In persons with tophi, prophylaxis should be continued until all tophaceous deposits have been dissolved. Perhaps the best way to follow the need for gout attack prophylaxis is with the use of musculoskeletal ultrasound to determine when all tophaceous material has been dissolved away. ${ }^{151-154,180,181}$

\section{Hypouricemic therapy Introduction}

Moderation of alcohol consumption, diets tailored to control portion sizes, maintenance of ideal body weight and reducing insulin resistance ${ }^{34}$ are lifestyle changes that are recommended in contrast to use of an unpalatable low purine diet. Specific foods that seem to decrease uric acid levels include dairy products, coffee and vitamin C. Increased levels are associated with red meat, fructose (sweetened beverages) and beer. Unfortunately, the maximum serum urate reduction achieved by diet alone is typically only $\sim 1 \mathrm{mg} / \mathrm{dL}$ or up to $15 \%$ (unless accompanied by significant weight reduction), which makes pharmacologic options necessary for most patients with gout. The role of diet has recently been reviewed. ${ }^{182,183}$

\section{Role of diet}

Over the past 20 years, the average weight of American men has increased from 168 pounds (76 kg) to approximately 180 pounds $(82 \mathrm{~kg})$, and women from 142 pounds $(64 \mathrm{~kg})$ to 152 pounds $(69 \mathrm{~kg}) .{ }^{184}$ According to the National Institute of Diabetes and Digestive and Kidney Diseases (NIDDK), about two-thirds of Americans are overweight (BMI $\geq 25$ ) and nearly one-third are obese $(\mathrm{BMI} \geq 30)$. ${ }^{185}$ The proportion of obese persons increased from $13.3 \%$ to $32.1 \%$ since 1960 . In addition to gout, overweight and obesity are associated with type II diabetes, coronary artery disease, hypertension, stroke, hyperlipidemia, gallbladder disease, degenerative joint disease, sleep apnea and several types of cancer (including breast, colorectal, endometrial and kidney). Choi and colleagues found that the relative risk of gout was 1.95 for men with a BMI of 25 to 29.3 and 2.33 for men whose BMI was 30 to 34.9 and 2.97 for a BMI of $\geq 35$, compared with men whose BMI was 21 to $22.9 .{ }^{186}$ In summary, the major contribution of food to gout, at least in the current world epidemic, appears to be simply too much.

Perhaps surprisingly, there is a strong correlation between intake of sugar-containing soft drinks and serum uric acid levels. After adjusting for other variables such as body weight, Choi and colleagues found that those consuming four or more servings per day had uric acid levels on average $0.42 \mathrm{mg} / \mathrm{dL}$ higher than those with no intake of sweetened soft drinks, and the risk of hyperuricemia was increased 1.8-fold. ${ }^{187}$ In another study looking at males alone, the association was even stronger. ${ }^{188}$ Unfortunately there was also an association with consumption of fructose-containing fruits such as apples and oranges. (One could be forgiven for thinking that consumption of an apple a day is somehow healthier than drinking a pint of fruit juice.) Interestingly, consumption of cherries and vegetable protein has been associated with decreased risk. ${ }^{189}$ Schlesinger notes that an acute purine load can raise serum uric acid level by 1 to $2 \mathrm{mg} / \mathrm{dL}$ within 24 hours, sufficient to account for gout attacks occurring after dietary indiscretions on holidays. ${ }^{189}$

Patients often ask what they can do to improve their gout, although enthusiasm is often dampened by the recommendation to lose weight and to reduce alcohol consumption. Furthermore, although weight loss ultimately helps, fasting or near fasting can actually provoke gout attacks, presumably due to ketosis. ${ }^{190}$

When it comes to gout (in contrast to the situation with driving under the influence) all alcohol may not be equivalent. Beer (which has high purine content) seems to raise uric acid levels more per ounce of alcohol ingested and seems to be associated with a higher risk of gout than distilled spirits. ${ }^{191}$ Modest intake of wine (1 or 2 glasses per day) was not significantly associated with increased risk of gout.

\section{Cherry juice}

Many patients have heard that cherry juice is good for gout. But is it? A number of websites that offer cherry products for sale assure us that it is. A PubMed search combining gout with permutations of the word cherry turned up exactly 2 interventional trials. In one study, plasma urate levels declined $14.5 \% 5$ hours following ingestion of $280 \mathrm{~g}$ of red 
Bing cherries following an overnight fast. Other fruits were not effective. The subjects of the study were 10 healthy premenopausal women of normal weight with a normal mean plasma urate level. ${ }^{192} \mathrm{~A}$ trial of cherry juice in marathon runners showed a 2 to $3 \mathrm{mg} / \mathrm{dL}$ lower uric acid level post-race compared with placebo, but in that particular trial it was unclear if cherry juice enhanced uric acid excretion or decreased uric acid production. ${ }^{193}$ The baseline uric acid level was also slightly lower in the cherry juice group. Both a hypouricemic effect and an anti-inflammatory effect have been attributed to cherry juice. ${ }^{193,194}$

The hypouricemic effect of cherries may not be attributable to the vitamin $\mathrm{C}$ content. While acerola cherries are very high in vitamin C (4700 mg/280 g), most American varieties contain much less $(19.6 \mathrm{mg} / 280 \mathrm{~g}$ for sweet cherries, $28 \mathrm{mg} / 280 \mathrm{~g}$ for tart cherries). ${ }^{195}$ One cup of raw cherries (with pits) weighs $140 \mathrm{~g}$ (sweet) or $155 \mathrm{~g}$ (tart). ${ }^{195}$ A study done in 1950 of 12 gout patients suggested that 0.5 pound $(0.2 \mathrm{~kg})$ of cherries (several varieties were effective) or an equivalent amount of cherry juice prevented gout attacks. ${ }^{196}$ The mechanism of action is unclear. It is unfortunate that there is a dearth of data about such a wholesome and good-tasting potential remedy for gout.

\section{Vitamin C}

Does vitamin $\mathrm{C}$ reduce uric acid levels? In one small study, $4 \mathrm{~g}$ caused a uricosuric effect within a few hours. A few subjects took $8 \mathrm{~g} /$ day and were noted to have reduced serum uric acid by 1.2 to $3.1 \mathrm{~g} / \mathrm{dL} .{ }^{197}$ A later prospective cohort study found that each $500 \mathrm{mg}$ increase in vitamin $\mathrm{C}$ intake was associated with a multivariate relative risk of 0.83 for gout compared with those who took no supplement. ${ }^{198}$ This subject was also reviewed by Gao and colleagues. ${ }^{199}$

\section{Pharmacological urate-lowering strategies}

Hypourecemic therapy should be considered for most gouty patients, including those with end stage renal disease and nephrolithiasis. The main reason to use hypourecemic treatment is to prevent long-term complications of gout such as urate nephropathy, urate kidney stones, development of tophi and joint damage. Once the patient has suffered 1 attack of acute gout, the likelihood of recurrent attacks is extremely high. In patients not treated with urate-lowering drugs, $62 \%$ will experience a recurrence within 1 year of the initial attack, $78 \%$ by 2 years, and $89 \%$ by 5 years. ${ }^{200}$ For patient comfort, it is important to reduce or eliminate gouty flares. Thus, once urate-lowering medication is begun, the treatment is not intermittent; it is continuous and lifelong.
Uric acid level should be maintained below the solubility concentration of $6.8 \mathrm{mg} / \mathrm{dL}$, preferably below $6.0 \mathrm{mg} / \mathrm{dL}$. Still, some patients may continue to have clinically important deposits of MSU and/or attacks. Hypourecemic agents should not be started during the acute attack as that can exacerbate a flare. We recommend that patients who experience acute attacks while taking a hypourecemic agent do not discontinue the agent because the subsequent increase in serum uric acid level may worsen the attack.

On the other hand, hypourecemic therapy may not be necessary for patients with a frequency of gout attacks less then 2 or 3 times per year, who have no tophaceous deposits, and who have mildly elevated uric acid levels that may be amenable to lifestyle changes and nonpharmacological treatment (see above). Hypouricemic treatment may not be indicated in very elderly patients who may not require long-term prophylaxis against renal or joint damage. Such patients may do very well simply with colchicine prophylaxis against acute attacks.

Allopurinol and febuxostat (but not probenecid) both provide effective prophylaxis against nephrolithiasis in most gouty patients.

\section{Allopurinol}

Allopurinol has been the cornerstone of urate-lowering treatment in the US since 1966, but despite potent xanthine oxidase inhibition and urate-lowering properties, allopurinol is commonly underdosed or poorly adhered to in long-term treatment. ${ }^{201-203}$

In patients with normal renal and liver function, allopurinol is generally started in a dose of $100 \mathrm{mg}$ /day and increased by $100 \mathrm{mg} /$ day weekly until $300 \mathrm{mg} /$ day is being taken. The goal is to maintain a serum uric acid level $<6.0 \mathrm{mg} / \mathrm{dL}$. The dose may be gradually increased to $800 \mathrm{mg} /$ day in patients with normal renal function, but the risk of serious idiosyncratic toxicity increases at higher doses, and with renal insufficiency (see below). Despite the wide dose range over which allopurinol is approved in the US, only a single randomized controlled trial has evaluated the efficacy and safety of allopurinol in doses exceeding $300 \mathrm{mg} /$ day. ${ }^{204}$

The most common adverse effects are gastrointestinal upset and rash. The incidence of rash is estimated at $2 \%{ }^{205,206}$ Unfortunately, serious toxicity is completely unpredictable and is considered to be allergic in nature. Allopurinol-induced rash usually resolves upon discontinuation of the drug, but rechallenge may lead to life-threatening toxic epidermal necrolysis. In the past, persons who required allopurinol could sometimes successfully undergo desensitization, ${ }^{207}$ but this is less commonly done since febuxostat has provided an 
alternative for allopurinol-allergic patients. The occurrence of xanthine urinary calculi is a theoretical possibility under low urinary flow conditions.

One rare but exceedingly important reaction to allopurinol is the allopurinol hypersensitivity syndrome (AHS), which consists of rash (sometimes severe as in toxic epidermal necrolysis or exfoliative dermatitis), eosinophilia, leukocytosis, fever, hepatitis and progressive renal failure (usually due to interstitial nephritis). ${ }^{206}$ One particularly alarming feature of the syndrome is that it often is relentlessly progressive (and fatal) despite discontinuation of allopurinol and institution of corticosteroid therapy. ${ }^{208,209}$ There are no published trials or case reports that examined immunosuppressive treatments. The incidence of AHS is estimated at $\sim 0.1 \%$. ${ }^{205}$ Allopurinol is one of the more commonly used drugs that can cause severe hypersensitivity reactions. ${ }^{210}$ Risk factors for AHS include higher dose, renal insufficiency, diuretic use and higher oxypurinol concentrations. ${ }^{211}$ There may also be a genetic predisposition. HLA-B*501 was found in $100 \%$ of 51 Taiwanese patients with severe cutaneous reactions to allopurinol, but in only $20 \%$ of the general population. ${ }^{212}$

According to the allopurinol prescribing information, ${ }^{213}$ the frequency of hypersensitivity reactions may be increased in patients with decreased renal function who are receiving thiazides concurrently. It is also stated in the package insert that patients with decreased renal function require lower doses. "Therefore, a dose of $100 \mathrm{mg} /$ day or $300 \mathrm{mg}$ twice a week or perhaps less may be sufficient ..." With a creatinine clearance of 10 to $20 \mathrm{~mL} / \mathrm{min}$, a dose of $200 \mathrm{mg}$ "is suitable", and for creatinine clearance between 3 and $10 \mathrm{~mL} / \mathrm{min}$, the dose "should not exceed $100 \mathrm{mg}$ ".

Allopurinol dosing in the presence of renal insufficiency has recently been reviewed. ${ }^{205,214,215}$ The main concern has been accumulation of the major metabolite oxypurinol which has a half-life of 18 to 30 hours in the presence of normal renal function, increasing up to a week in those with severely impaired renal function. ${ }^{205,216}$ Unfortunately reductions in serum uric acid level do not correlate well with oxypurinol concentrations, hence some persons are resistant to the urate-lowering effects even at very high serum levels of oxypurinol.

Recommendations for lower doses of allopurinol in the presence of renal insufficiency stem mainly from reports that most patients with AHS had pre-existing renal insufficiency and were receiving full doses of allopurinol. ${ }^{209,217,218}$ Critics point out that the relationship between oxypurinol concentrations and AHS remains unproven, ${ }^{219,220}$ and that no study has systematically demonstrated that dosage reduction in renal insufficiency reduces the risk of severe AHS. Some studies have found no relationship of AHS with dose in renal insufficiency. ${ }^{212,219,220}$ In other words, it is suggested that the renal insufficiency itself confers the risk, not the dose of allopurinol. ${ }^{219}$ Lastly, the increased risk of AHS (if any) must be balanced against the risk of inadequate control of gout that often follows from using the lower recommended doses.

The frequency of gouty attacks seems to decline once CKD patients are placed on dialysis. ${ }^{221,222}$ Nevertheless, when allopurinol is required by patients undergoing dialysis, it may be started at $100 \mathrm{mg}$ every other day, to be administered postdialysis. If dialysis is performed daily, then an additional $50 \%$ may be required post-dialysis. ${ }^{205}$ Interestingly, the package insert makes no mention of dialysis. ${ }^{213}$ It is noteworthy that the phosphate binder sevelamer has been reported to have a modest urate-lowering effect and may be useful as an adjunct. ${ }^{205,223}$

Unfortunately gout becomes more frequent in transplant recipients. Minimizing diuretic use and calcineurin dose seems to be important in renal transplant recipients. The management of gout in transplant patients can be difficult and has been reviewed. ${ }^{224,225}$

Although allopurinol and uricosuric agents may be used together, it is worth noting that uricosuric agents also tend to increase the excretion of oxypurinol, resulting in either a reduction of efficacy or a need for additional allopurinol.

The prescribing information Dosage and Administration section notes that the average dose is 400 to $600 \mathrm{mg}$ /day for patients with moderately severe tophaceous gout (and presumably with normal renal function). Doses above $400 \mathrm{mg} /$ day should be administered in divided doses. It is best to begin with $100 \mathrm{mg} /$ day to minimize the risk of acute gout attacks and increase by $100 \mathrm{mg}$ /day per week. The effect of any given dose adjustment upon serum uric acid level will generally be apparent by 1 week, occasionally longer if many tophaceous deposits are present. The maximum recommended dose is $800 \mathrm{mg}$ /day.

Allopurinol has life-threatening interactions with azathioprine and 6-mercaptopurine because metabolism of these immunosuppressive agents is inhibited by allopurinol, but they may be used together with proper dosage adjustment. Allopurinol may prolong anticoagulation times in those taking warfarin and may elevate theophylline levels by inhibiting metabolism of this purine derivative.

Neither allopurinol nor febuxostat is indicated for asymptomatic hyperuricemia, although this was fairly common practice in years past. ${ }^{226,227}$ Given the emerging risks of sustained hyperuricemia, ${ }^{16,64,228}$ debate on this question may be renewed, but the benefits of lowering uric acid must be balanced against the risk of serious reactions. 


\section{Febuxostat}

Febuxostat was approved in the US in 2008, the first FDAapproved hypouricemic agent in more than 40 years. It is a nonpurine inhibitor of xanthine oxidase. It has several potential advantages over allopurinol including tolerability in those who are allopurinol-hypersensitive, better retention of efficacy in renal insufficiency (without an increased incidence of hypersensitivity reactions, based on limited data), better efficacy than allopurinol in many persons and possibly more rapid dissolution of tophi. Potential problems include liver enzyme elevation, possibly more gastrointestinal symptomatology than with allopurinol and a small increase in the risk of vascular events compared with allopurinol. Questions that are still unanswered include dose and efficacy in patients with advanced renal failure or on dialysis, and whether there are special hazards in this population. Clinical trials are ongoing in this population.

Information on efficacy in persons with normal renal function comes from a short-term, randomized controlled trial. ${ }^{229}$ The primary endpoint for the trial was the proportion of patients with a serum uric acid level $<6.0 \mathrm{mg} / \mathrm{dL}$. This endpoint was achieved by $56 \%, 76 \%$ and $94 \%$ of those taking $40 \mathrm{mg}, 80 \mathrm{mg}$ and $120 \mathrm{mg} /$ day of febuxostat, respectively, and by $0 \%$ in the placebo group. Perhaps surprisingly, the rate of gout flares in the $40 \mathrm{mg}$ group ( $35 \%$ ) was similar to that in the placebo group (37\%). The rate of gout flares increased to $55 \%$ in those taking $120 \mathrm{mg}$. Concomitant colchicine provided effective prophylaxis against flares, reducing the rate to $8 \%$ to $13 \%$. Doses of febuxostat approved in the US are $40 \mathrm{mg}$ and $80 \mathrm{mg} /$ day.

A subsequent 1-year trial compared doses of $80 \mathrm{mg}$ and $120 \mathrm{mg}$ with allopurinol $300 \mathrm{mg} .{ }^{230}$ Entry criteria included a serum uric acid $>8.0 \mathrm{mg} / \mathrm{dL}$ and a serum creatinine $<1.50 \mathrm{mg} / \mathrm{dL}$. (This study has been criticized because the dose of allopurinol could not be increased, as it typically would in real life). By the final visit, a serum uric acid level $<6.0 \mathrm{mg} / \mathrm{dL}$ was achieved by $81 \%, 82 \%$ and $39 \%$, respectively. In subjects with a baseline serum uric acid level $>10.0 \mathrm{mg} / \mathrm{dL}$, the primary endpoint was achieved by $47 \%, 44 \%$ and $8 \%$ respectively. There was a trend toward more rapid dissolution of tophi in the febuxostat groups ( $83 \%$ reduction in tophus surface area in the $40 \mathrm{mg}$ febuxostat group versus $50 \%$ reduction in the allopurinol group), although this difference did not achieve statistical significance, perhaps because a relatively small percentage of subjects had tophi at baseline. (Our observations in clinical practice suggest that febuxostat dissolves tophi significantly faster than allopurinol.) There were more rashes in the allopurinol group. The incidence of liver enzyme elevation was similar in all 3 groups. It is difficult to know if febuxostat is superior to allopurinol in dissolving tophi since the dose of allopurinol was not increased beyond $300 \mathrm{mg} /$ day, as it would be in real life.

Doses above $120 \mathrm{mg} /$ day did not significantly reduce uric acid further. ${ }^{231}$

According to the package insert, there are insufficient data to make a recommendation in patients with severe renal insufficiency $(<30 \mathrm{~mL} / \mathrm{min})$, and "caution is advised," but it is not considered a contraindication. ${ }^{179}$ The $\mathrm{C}_{\max }$ and area under the plasma concentration time curve for febuxostat and for 3 active metabolites are increased in severe renal insufficiency. There are no published data in patients receiving dialysis. ${ }^{179}$

Febuxostat works fairly quickly; treatment begins with $40 \mathrm{mg} / \mathrm{day}$. If serum uric acid is not less than $6.0 \mathrm{mg} / \mathrm{dL}$ by 2 weeks, the dose may be increased to $80 \mathrm{mg} /$ day. Mean reduction in serum uric acid level is $40 \%$ and $56 \%$ at $40 \mathrm{mg}$ /day and $80 \mathrm{mg}$ /day respectively and is similar in those with and without renal insufficiency, in contrast to allopurinol. Halflife of the parent compound and of major metabolites is significantly prolonged in persons with renal insufficiency, but this does not appear to be clinically important. Elimination is partially hepatic, allowing greater dosage flexibility in those with renal impairment. Transaminase elevation greater than 3 times the upper limit of normal occurs in 2\% to $3 \%$ of patients and is similar in this regard to allopurinol. It is recommended to follow liver enzymes periodically, certainly by 2 months after beginning treatment.

The association of cardiovascular events (cardiovascular death, nonfatal myocardial infarction and nonfatal stroke) with allopurinol treatment remains unsettled. In Phase 3 studies, rates of events per 100 patient-years of exposure were: placebo 0 , febuxostat $40 \mathrm{mg} 0$, febuxostat $80 \mathrm{mg} 1.09$ and allopurinol $0.60 .{ }^{179}$ In long-term extension studies, the rates were 0.97 for febuxostat $80 \mathrm{mg}$ and 0.58 for allopurinol (there was no placebo group). In all these cases the confidence intervals overlapped, but there seems to be a trend. As noted in the package insert, ${ }^{179}$ a causal relationship has not been established. Cardiovascular disease is not a contraindication to the use of febuxostat or allopurinol, but the febuxostat package insert further recommends that the practitioner "monitor for signs and symptoms of MI and stroke" ${ }^{179}$ Given the ability of both febuxostat and allopurinol to dissolve tophi, it is hypothesized that these agents may destabilize plaque (which may contain urate) in the walls of blood vessels.

Febuxostat is expected to be at least as effective as allopurinol for prophylaxis of nephrolithiasis, based on its mechanism of action. 
Because febuxostat is a xanthine oxidase inhibitor, it prolongs the half-life of purine analogs such as azathioprine and 6-mercaptopurine and theophylline, similar to the case with allopurinol. This is a potentially life-threatening interaction, and according to the package insert, febuxostat is contraindicated with the above 3 drugs. Hypersensitivity to allopurinol is not a contraindication to use of febuxostat.

Febuxostat is more expensive than generic allopurinol, costing approximately US\$166 for 30 tablets.

In clinical trials, adverse effects associated with febuxostat included rash $(<2 \%$ incidence), but without reported severe cutaneous reactions. Incidence of rash with febuxostat $80 \mathrm{mg} /$ day was similar to that with allopurinol $300 \mathrm{mg} /$ day. Diarrhea and elevated hepatic transaminases occurred in small proportions of patients. In current clinical practice, to contain drug costs, the primary use of febuxostat is reserved for patients with allopurinol hypersensitivity, intolerance, or treatment failure, including those in whom uricosuric therapy is not indicated or has failed.

\section{Probenecid}

Hyperuricemia in the vast majority ( $85 \%$ to $90 \%$ ) of gouty patients results from impaired renal uric acid excretion rather than from overproduction. ${ }^{232}$ In these individuals, renal uric acid clearance is subnormal $(<6 \mathrm{~mL} / \mathrm{min})$, so that maintenance of the balance between urate production and disposal can be achieved only at a saturating serum urate level, a circumstance predisposing to urate crystal formation and deposition. Although uricosuric agents provide a rational and even preferable means to lower serum uric acid in these patients, this class of urate-lowering agents is prescribed infrequently in the US. ${ }^{201}$ In general, the ideal candidate for a uricosuric agent is the gouty patient who is younger than 60 years of age, has a creatinine clearance greater than $80 \mathrm{~mL} / \mathrm{min}$, a 24-hour urinary uric acid excretion of less than $800 \mathrm{mg}$ on a general diet and no history of renal calculi.

Probenecid is the only potent uricosuric agent available in the US. It acts by interfering with renal urate or anion exchange, thus inhibiting proximal tubular uric acid reabsorption. ${ }^{88}$ The infrequent use of probenecid $(<5 \%$ of treated gout patients) likely reflects several circumstances: the availability of allopurinol and febuxostat; the requirement for multiple daily dosing; diminished or complete loss of uratelowering efficacy in gout patients with moderate or more advanced CKD; relative contraindication in patients with prior urolithiasis or uric acid overproduction; a perception that it is less effective than allopurinol; many drug-drug interactions. The maintenance dosage of probenecid ranges from $500 \mathrm{mg} /$ day to $3.0 \mathrm{~g} /$ day and must be taken in divided doses. Rash, gastrointestinal complaints and hypersensitivity occur in approximately $5 \%$ of patients. Although serious toxicity is rarely reported (it is perceived as safer than allopurinol in that regard), approximately one-third of patients become intolerant and discontinue it.

Alkalinization of the urine has been recommended when using a uricosuric agent to decrease the risk of forming uric acid calculi. Some authors believe that adequate hydration may be sufficient to avoid this complication.

\section{Benzbromarone}

Benzbromarone, a uricosuric drug not commercially available in the US and many other countries, is a potent but potentially hepatotoxic agent. The drug is metabolized by the hepatic cytochrome P450 system and is effective in patients with moderate renal impairment. "Standard doses" of benzbromarone (100 mg/day) produce greater hypouricemic effects than 'standard doses' of allopurinol (300 mg/day) or probenecid (1000 mg/day). ${ }^{233,234}$ In a recently published study of "allopurinol-intolerant" patients, $92 \%$ of patients given benzbromarone were successfully treated to sUA $<5 \mathrm{mg} / \mathrm{dL}$ compared with $65 \%$ of patients given probenecid. ${ }^{234}$

Sulfinpyrazone, another uricosuric agent, is no longer available in the US, mainly because of the potential for serious gastrointestinal toxicity.

\section{Losartan and fenofibrate}

Losartan and fenofibrate are drugs developed for indications other than urate-lowering but have modest uricosuric effects. They are thus useful urate-lowering adjuncts in selected patients. Urate-lowering effects of fenofibrate or losartan are generally in the range of $12 \%$ to $20 \%$, respectively. ${ }^{235}$

\section{Effect of aspirin}

Aspirin has a urate-retaining effect on the kidney at low doses $(<3 \mathrm{~g} /$ day), but a marked uricosuric effect at high doses ( $>3 \mathrm{~g} /$ day). Even mini-dose aspirin can affect serum uric acid. In one study of elderly patients, aspirin in a dose of $75 \mathrm{mg}$ /day raised sUA by $0.27 \mathrm{mg} / \mathrm{dL}, 150 \mathrm{mg} /$ day raised it less and $325 \mathrm{mg} /$ day did not raise sUA. ${ }^{10}$ Creatinine clearance declined $12 \%$ to $13 \%$ regardless of dose, corresponding to a serum creatinine rise of $\sim 0.04 \mathrm{mg} / \mathrm{dL}$. Interestingly, significant effects on creatinine clearance were largely confined to subjects with lower serum albumin levels, presumably because of higher free salicylate levels in that group. Concomitant diuretic use seemed to increase the aspirin effect. 


\section{Uricase}

Uricase could enable accelerated dissolution of tophi over intervals of weeks or months instead of years. Uricase has the potential to dramatically improve the chronic crippling effects of tophaceous gout in those who are intolerant or unresponsive to current therapies.

Pegylation of uricase helps to suppress its immunogenicity and to increase its half-life. In one pivotal, Phase 3 study in patients with particularly severe gout, $\sim 70 \%$ of whom had visible tophi, treatment with recombinant, pegylated intravenous uricase (pegloticase) $8 \mathrm{mg}$ every 2 weeks achieved the target serum uric acid level of $<6 \mathrm{mg} / \mathrm{dL}$ at 6 months in $\sim 42 \% .{ }^{12}$ This regimen also achieved complete resolution of tophi in $20 \%$ of patients by 13 weeks and $\sim 40 \%$ by 25 weeks. The immunogenicity of uricases, including pegloticase, has limited their tolerability and efficacy. Antibodies to these drugs develop in most patients, despite the use of pegylation, and infusion reactions are common. Such reactions were observed in more than a quarter of patients. High titers of antipegloticase antibodies were linked with infusion reactions and were often associated with loss of efficacy. An important point to note is that in the first few months of pegloticase therapy, acute gout flares are frequent, up to $80 \%$ of patients in one study ${ }^{12}$ but taper off with continued therapy in responders.

Uricase treatment has the capability to induce oxidative stress mediated by generation of hydrogen peroxide. ${ }^{236}$ The presence of glucose-6-phosphate dehydrogenase deficiency is an exclusion criterion for uricase treatment, to prevent drug-induced methemoglobinemia and hemolysis. Shortterm and long-term safety are not yet clearly defined for uricase therapy. It has been proposed that uricase therapy should be reserved for selected patients who could potentially benefit from accelerated tophus debulking, for example, to resolve incapacitating tophi linked with active synovitis, or under circumstances where patients have failed to respond to appropriate doses of oral urate-lowering therapies. At the time of writing (August, 2010) pegloticase (Krystexxa ${ }^{\mathrm{TM}}$; Savient Pharmaceuticals, Inc.) has been resubmitted to the FDA for approval for selected gout indications.

\section{RDEA594}

The critical importance of URAT-1 to uric acid homeostasis has made it a prime target for therapeutic manipulation. RDEA594 is a novel inhibitor of URAT- 1 that was recently found in a Phase 2a trial to perform about as well as the allopurinol comparator, and was well tolerated. ${ }^{237}$ Studies are ongoing. RDEA594 is a major metabolite of RDEA806, a non-nucleoside reverse transcriptase inhibitor currently in trials for treatment of HIV. ${ }^{238}$

\section{Chronic kidney disease and renal transplant patients}

Treatment of the acute gout attack in patients with renal insufficiency has been recently reviewed. ${ }^{215}$ NSAIDs are frequently not an option in such cases. Colchicine may be used, but the maintenance dose must be reduced. There is a real long-term risk of myopathy and/or neuropathy in renal insufficiency with maintenance doses as low as $1.2 \mathrm{mg} /$ day, even with relatively short courses. Cyclosporine also interacts with colchicine to increase colchicine levels. Corticosteroids frequently become the agents of choice. While local joint injections result in the least systemic exposure, systemic steroids are frequently necessary. Systemic corticosteroids must be administered in divided doses 2 or even 3 times per day to achieve rapid control.

Whereas most gouty dialysis patients enjoy a marked reduction in the frequency of gout attacks, the opposite occurs postkidney transplant. Patients receiving cyclosporine have been reported to have an incidence between $3.5 \%$ and $28 \%$; without cyclosporine the incidence is between $0 \%$ and $8 \%$. Several mechanisms of action have been proposed. ${ }^{215,225}$ Tacrolimus is slightly less offensive in its effect on uric acid handling. ${ }^{215}$

There are no published data on the use of febuxostat in transplant patients. Allopurinol remains the hypouricemic agent of choice as a rule, but there is a potentially lifethreatening interaction with azathioprine, as noted above.

\section{Disclosure}

The authors have no financial disclosures and no conflicts of interest with this work.

\section{References}

1. Choi HK, Mount DB, Reginato AM. Pathogenesis of gout. Ann Intern Med. 2005;143(7):499-516.

2. Choi HK, Curhan G. Gout: epidemiology and lifestyle choices. Curr Opin Rheumatol. 2005;17(3):341-345.

3. Nriagu JO. Saturnine gout among Roman aristocrats. Did lead poisoning contribute to the fall of the Empire? N Engl J Med. 1983;308(11): 660-663.

4. Healey LA. Port wine and the gout. Arthritis Rheum. 1975;18 Suppl 6: 659-662.

5. Steinbock RT. Lead ingestion in history. N Engl J Med. 1979; 301(5):277.

6. Hak AE, Choi HK. Lifestyle and gout. Curr Opin Rheumatol. 2008;20(2): 179-186.

7. Saag KG, Choi H. Epidemiology, risk factors, and lifestyle modifications for gout. Arthritis Res Ther. 2006;8 Suppl 1:S2.

8. Saag KG, Mikuls TR. Recent advances in the epidemiology of gout. Curr Rheumatol Rep. 2005;7(3):235-241.

9. Kahn AM. Effect of diuretics on the renal handling of urate. Semin Nephrol. 1988;8(3):305-314. 
10. Caspi D, Lubart E, Graff E, Habot B, Yaron M, Segal R. The effect of mini-dose aspirin on renal function and uric acid handling in elderly patients. Arthritis Rheum. 2000;43(1):103-108.

11. Schumacher HR Jr, Becker MA, Wortmann RL, et al. Effects of febuxostat versus allopurinol and placebo in reducing serum urate in subjects with hyperuricemia and gout: a 28-week, phase III, randomized, double-blind, parallel-group trial. Arthritis Rheum. 2008;59(11): 1540-1548.

12. Sundy JS, Becker MA, Baraf HS, et al. Reduction of plasma urate levels following treatment with multiple doses of pegloticase (polyethylene glycol-conjugated uricase) in patients with treatment-failure gout: Results of a phase II randomized study. Arthritis Rheum. 2008;58(9):2882-2891.

13. Sherman MR, Saifer MG, Perez-Ruiz F. PEG-uricase in the management of treatment-resistant gout and hyperuricemia. Adv Drug Deliv Rev. 2008;60(1):59-68.

14. Farkouh ME, Greenberg BP. An evidence-based review of the cardiovascular risks of nonsteroidal anti-inflammatory drugs. Am J Cardiol. 2009;103(9):1227-1237.

15. Edwards NL. The role of hyperuricemia and gout in kidney and cardiovascular disease. Cleve Clin J Med. 2008;75 Suppl 5:S13-S16.

16. Feig DI, Kang DH, Johnson RJ. Uric acid and cardiovascular risk. N Engl J Med. 2008;359(17):1811-1821.

17. Schlesinger N, Dalbeth N, Perez-Ruiz F. Gout - what are the treatment options? Expert Opin Pharmacother. 2009;10(8):1319-1328.

18. Thiele RG, Schlesinger N. Ultrasonography shows disappearance of monosodium urate crystal deposition on hyaline cartilage after sustained normouricemia is achieved. Rheumatol Int. 2010;30(4):495-503.

19. Perez-Ruiz F, Dalbeth N, Urresola A, de Miguel E, Schlesinger N. Gout Imaging of gout: findings and utility. Arthritis Res Ther. 2009; 11(3):232.

20. Lee SJ, Hirsch JD, Terkeltaub R, et al. Perceptions of disease and health-related quality of life among patients with gout. Rheumatology (Oxford). 2009;48(5):582-586.

21. Singh JA. Quality of life and quality of care for patients with gout. Curr Rheumatol Rep. 2009;11(2):154-160.

22. Singh JA, Strand V. Gout is associated with more comorbidities, poorer health-related quality of life and higher healthcare utilisation in US veterans. Ann Rheum Dis. 2008;67(9):1310-1316.

23. Roddy E, Zhang W, Doherty M. Is gout associated with reduced quality of life? A case-control study. Rheumatology (Oxford). 2007;46(9): 1441-1444.

24. Winzenberg T, Buchbinder R; Cochrane Musculoskeletal Group review: acute gout. Steroids or NSAIDs? Let this overview from the Cochrane Group help you decide what's best for your patient. J Fam Pract 2009;58(7):E1-E4.

25. Kim SY, Choi HK. Gout and quality of life. J Rheumatol. 2009;36(5): 865-868

26. Shulten P, Thomas J, Miller M, Smith M, Ahern M. The role of diet in the management of gout: a comparison of knowledge and attitudes to current evidence. J Hum Nutr Diet. 2009;22(1):3-11.

27. Weaver AL. Epidemiology of gout. Cleve Clin J Med. 2008;75 Supp1 5: S9-S12.

28. Campion EW, Glynn RJ, DeLabry LO. Asymptomatic hyperuricemia. Risks and consequences in the Normative Aging Study. Am J Med. 1987 Mar;82(3):421-426.

29. Marinello E, Riario-Sforza G, Marcolongo R. Plasma folliclestimulating hormone, luteinizing hormone, and sex hormones in patients with gout. Arthritis Rheum. 1985;28(2):127-131.

30. Rosen R, Tomer Y, Carel R, Weinberger A. Serum 17-beta-estradiol and testosterone levels in asymptomatic hyperuricaemic men. Clin Rheumatol. 1994;13(2):219-223.

31. Rho YH, Choi SJ, Lee YH, et al. The prevalence of metabolic syndrome in patients with gout: a multicenter study. J Korean Med Sci. 2005;20(6):1029-1033.

32. Onat A, Uyarel H, Hergenc G, et al. Serum uric acid is a determinant of metabolic syndrome in a population-based study. Am J Hypertens. 2006;19(10):1055-1062.
33. Takahashi S, Yamamoto T, Moriwaki Y, Tsutsumi Z, Higashino K. Impaired lipoprotein metabolism in patients with primary gout-influence of alcohol intake and body weight. Br J Rheumatol. 1994;33(8): 731-734.

34. Genelhu VA, Celoria BM, Duarte SF, Cabello PH, Francischetti EA. Not all obese subjects of multiethnic origin are at similar risk for developing hypertension and type 2 diabetes. Eur J Intern Med. 2009;20(3): 289-295.

35. Choi HK. Diet, alcohol, and gout: how do we advise patients given recent developments? Curr Rheumatol Rep. 2005;7(3):220-226.

36. Torralba TP, Bayani-Sioson PS. The Filipino and gout. Semin Arthritis Rheum. 1975;4(4):307-320.

37. Kaplan H, Klatskin G. Sarcoidosis, psoriasis, and gout: syndrome or coincidence? Yale J Biol Med. 1960;32:335-352.

38. Yu TF. Secondary gout associated with myeloproliferative diseases. Arthritis Rheum. 1965;8(5):765-771.

39. Brutsche RL, Doerner AA. Chronic lymphocytic leukemia; report of a case with marked uric acid crystalluria. AMA Arch Intern Med. 1956; 97(6):817-819.

40. Ludwig GD. Saturnine gout; a secondary type of gout. AMA Arch Intern Med. 1957;100(5):802-812.

41. Kang EH, Lee EY, Lee YJ, Song YW, Lee EB. Clinical features and risk factors of postsurgical gout. Ann Rheum Dis. 2008;67(9):1271-1275.

42. Raj JM, Sudhakar S, Sems K, Carlson RW. Arthritis in the intensive care unit. Crit Care Clin. 2002;18(4):767-780.

43. Kurtzman NA. Coexistent sarcoidosis and gout. J Lancet. 1965;85: 195-196.

44. Rubin MR, Silverberg SJ. Rheumatic manifestations of primary hyperparathyroidism and parathyroid hormone therapy. Curr Rheumatol Rep. 2002;4(2):179-185

45. Kang HC, Chung DE, Kim DW, Kim HD. Early- and late-onset complications of the ketogenic diet for intractable epilepsy. Epilepsia. 2004;45(9):1116-1123.

46. Cameron JS, Simmonds HA. Hereditary hyperuricemia and renal disease. Semin Nephrol. 2005;25(1):9-18.

47. Kamatani N, Yamanaka H, Totokawa S, Kashiwazaki S, Higurashi M. Down syndrome with coexistent gout: report of six patients and possible reasons for the scarcity of descriptions of this association. Ann Rheum Dis. 1996;55(9):649-650.

48. Saigal R, Chakraborty A, Yadav RN, Prashant RK. Partial HPRT deficiency (Kelley-Seegmiller syndrome). J Assoc Physicians India. 2006;54:49-52.

49. Nyhan WL. Inherited hyperuricemic disorders. Contrib Nephrol. 2005;147:22-34.

50. Nakagawa $\mathrm{T}, \mathrm{Hu} \mathrm{H}$, Zharikov $\mathrm{S}$, et al. A causal role for uric acid in fructose-induced metabolic syndrome. Am J Physiol Renal Physiol. 2006;290(3):F625-F631.

51. Saglam F, Celik A, Sarioglu S, et al. Hyperuricemia influences chronic cyclosporine nephropathy. Transplant Proc. 2008;40(1):167-170.

52. White $\mathrm{M}$, Haddad $\mathrm{H}$, Leblanc $\mathrm{MH}$, et al. Conversion from cyclosporine microemulsion to tacrolimus-based immunoprophylaxis improves cholesterol profile in heart transplant recipients with treated but persistent dyslipidemia: the Canadian multicentre randomized trial of tacrolimus vs cyclosporine microemulsion. J Heart Lung Transplant. 2005;24(7): 798-809.

53. Noordzij TC, Leunissen KM, van Hooff JP. Renal handling of urate and the incidence of gouty arthritis during cyclosporine and diuretic use. Transplantation. 1991;52(1):64-67.

54. Nakagawa T, Tuttle KR, Short RA, Johnson RJ. Hypothesis: fructoseinduced hyperuricemia as a causal mechanism for the epidemic of the metabolic syndrome. Nat Clin Pract Nephrol. 2005;1(2):80-86.

55. Sanchez-Lozada LG, Tapia E, Bautista-Garcia P, et al. Effects of febuxostat on metabolic and renal alterations in rats with fructose-induced metabolic syndrome. Am J Physiol Renal Physiol. 2008;294(4):F710-F718.

56. Siu YP, Leung KT, Tong MK, Kwan TH. Use of allopurinol in slowing the progression of renal disease through its ability to lower serum uric acid level. Am J Kidney Dis. 2006;47(1):51-59. 
57. White JS. Misconceptions about high-fructose corn syrup: is it uniquely responsible for obesity, reactive dicarbonyl compounds, and advanced glycation endproducts? J Nutr. 2009;139(6):1219S-1227S.

58. White JS. Straight talk about high-fructose corn syrup: what it is and what it ain’t. Am J Clin Nutr. 2008;88(6):1716S-1721S.

59. Soleimani M. Dietary fructose, salt absorption and hypertension in metabolic syndrome: Toward a new paradigm. Acta Physiol (Oxf). 2010. [Epub ahead of print].

60. Akhavan T, Anderson GH. Effects of glucose-to-fructose ratios in solutions on subjective satiety, food intake, and satiety hormones in young men. Am J Clin Nutr. 2007;86(5):1354-1363.

61. Fessel WJ. Renal outcomes of gout and hyperuricemia. Am J Med. 1979;67(1):74-82.

62. Miranda-Carus E, Mateos FA, Sanz AG, Herrero E, Ramos T, Puig JG. Purine metabolism in patients with gout: the role of lead. Nephron. 1997;75(3):327-335.

63. Feig DI. Uric acid: a novel mediator and marker of risk in chronic kidney disease? Curr Opin Nephrol Hypertens. 2009;18(6):526-530.

64. Edwards NL. The role of hyperuricemia in vascular disorders. Curr Opin Rheumatol. 2009;21(2):132-137.

65. Kang DH, Han L, Ouyang X, et al. Uric acid causes vascular smooth muscle cell proliferation by entering cells via a functional urate transporter. Am J Nephrol. 2005;25(5):425-433.

66. Nakagawa T, Mazzali M, Kang DH, et al. Hyperuricemia causes glomerular hypertrophy in the rat. Am J Nephrol. 2003;23(1):2-7.

67. Nakagawa T, Kang DH, Ohashi R, et al. Tubulointerstitial disease: role of ischemia and microvascular disease. Curr Opin Nephrol Hypertens. 2003;12(3):233-241.

68. Gibson T, Rodgers V, Potter C, Simmonds HA. Allopurinol treatment and its effect on renal function in gout: a controlled study. Ann Rheum Dis. 1982;41(1):59-65.

69. Avram Z, Krishnan E. Hyperuricaemia - where nephrology meets rheumatology. Rheumatology (Oxford). 2008;47(7):960-964.

70. Whelton A, MacDonald P, Lloyd E, Lademacher C. Beneficial relationship of serum urate (sUA) reduction and estimated glomerular filtration rate (eGFR) improvement/maintenance in hyperuricemic gout subjects treated for up to 5.5 years with febuxostat (FEB) [abstract). 2008 American College of Rheumatology Meeting. San Francisco, CA; 2008.

71. Gaffo AL, Edwards NL, Saag KG. Gout. Hyperuricemia and cardiovascular disease: how strong is the evidence for a causal link? Arthritis Res Ther. 2009;11(4):240.

72. Shah A, Keenan RT. Gout, hyperuricemia, and the risk of cardiovascular disease: cause and effect? Curr Rheumatol Rep. 2010;12(2): $118-124$.

73. Roncal CA, Reungjui S, Sanchez-Lozada LG, et al. Combination of captopril and allopurinol retards fructose-induced metabolic syndrome. Am J Nephrol. 2009;30(5):399-404.

74. Nakagawa T, Mazzali M, Kang DH, Sanchez-Lozada LG, HerreraAcosta J, Johnson RJ. Uric acid - a uremic toxin? Blood Purif. 2006; 24(1):67-70.

75. Masuo K, Kawaguchi H, Mikami H, Ogihara T, Tuck ML. Serum uric acid and plasma norepinephrine concentrations predict subsequent weight gain and blood pressure elevation. Hypertension. 2003; 42(4):474-480.

76. Nagahama K, Inoue T, Iseki K, et al. Hyperuricemia as a predictor of hypertension in a screened cohort in Okinawa, Japan. Hypertens Res. 2004;27(11):835-841.

77. Nakanishi N, Okamoto M, Yoshida H, Matsuo Y, Suzuki K, Tatara K. Serum uric acid and risk for development of hypertension and impaired fasting glucose or Type II diabetes in Japanese male office workers. Eur J Epidemiol. 2003;18(6):523-530.

78. Annemans L, Spaepen E, Gaskin M, et al. Gout in the UK and Germany: prevalence, comorbidities and management in general practice 2000-2005. Ann Rheum Dis. 2008;67(7):960-966.

79. Krishnan E, Kwoh CK, Schumacher HR, Kuller L. Hyperuricemia and incidence of hypertension among men without metabolic syndrome. Hypertension. 2007;49(2):298-303.
80. Feig DI, Soletsky B, Johnson RJ. Effect of allopurinol on blood pressure of adolescents with newly diagnosed essential hypertension: a randomized trial. JAMA. 2008;300(8):924-932.

81. Tang Z, Cheng LT, Li HY, Wang T. Serum uric acid and endothelial dysfunction in continuous ambulatory peritoneal dialysis patients. Am J Nephrol. 2009;29(5):368-373.

82. Bergamini C, Cicoira M, Rossi A, Vassanelli C. Oxidative stress and hyperuricaemia: pathophysiology, clinical relevance, and therapeutic implications in chronic heart failure. Eur J Heart Fail. 2009;11(5): 444-452.

83. Mitsuhashi H, Yatsuya H, Matsushita K, et al. Uric acid and left ventricular hypertrophy in Japanese men. Circ J. 2009;73(4):667-672.

84. Bainbridge SA, von Versen-Hoynck F, Roberts JM. Uric acid inhibits placental system A amino acid uptake. Placenta. 2009;30(2):195-200.

85. Terkeltaub R, Bushinsky DA, Becker MA. Recent developments in our understanding of the renal basis of hyperuricemia and the development of novel antihyperuricemic therapeutics. Arthritis Res Ther. 2006; 8 Suppl 1:S4.

86. Benedict JD, Forsham PH, Stetten D Jr. The metabolism of uric acid in the normal and gouty human studied with the aid of isotopic uric acid. J Biol Chem. 1949;181(1):183-193.

87. Campo C, Ruilope LM, Segura J, Rodicio JL, Garcia-Robles R, GarciaPuig J. Hyperuricemia, low urine urate excretion and target organ damage in arterial hypertension. Blood Press. 2003;12(5-6):277-283.

88. Enomoto A, Kimura H, Chairoungdua A, et al. Molecular identification of a renal urate anion exchanger that regulates blood urate levels. Nature. 2002;417(6887):447-452.

89. Eraly SA, Vallon V, Rieg T, et al. Multiple organic anion transporters contribute to net renal excretion of uric acid. Physiol Genomics. 2008; 33(2):180-192.

90. Silverman W, Locovei S, Dahl G. Probenecid, a gout remedy, inhibits pannexin 1 channels. Am J Physiol Cell Physiol. 2008;295(3): C761-C767.

91. Enomoto A, Niwa T, Kanai Y, Endou H. Urate transporter and renal hypouricemia. Rinsho Byori. 2003;51(9):892-897.

92. So A, Thorens B. Uric acid transport and disease. J Clin Invest. 2010; 120(6):1791-1799.

93. Lipkowitz MS, Leal-Pinto E, Cohen BE, Abramson RG. Galectin 9 is the sugar-regulated urate transporter/channel UAT. Glycoconj J. 2004;19(7-9):491-498.

94. Choi HK, Zhu Y, Mount DB. Genetics of gout. Curr Opin Rheumatol. 2010;22(2):144-151.

95. Urano W, Taniguchi A, Anzai N, et al. Sodium-dependent phosphate cotransporter type 1 sequence polymorphisms in male patients with gout. Ann Rheum Dis. 2010;69(6):1232-1234.

96. Matsuo H, Takada T, Ichida K, et al. Common defects of ABCG2, a high-capacity urate exporter, cause gout: a function-based genetic analysis in a Japanese population. Sci Transl Med. 2009;1(5):5ra11.

97. Cheeseman C. Solute carrier family 2, member 9 and uric acid homeostasis. Curr Opin Nephrol Hypertens. 2009;18(5):428-432.

98. Dahan K, Devuyst O, Smaers M, et al. A cluster of mutations in the UMOD gene causes familial juvenile hyperuricemic nephropathy with abnormal expression of uromodulin. J Am Soc Nephrol. 2003;14(11): 2883-2893.

99. Rampoldi L, Caridi G, Santon D, et al. Allelism of MCKD, FJHN and GCKD caused by impairment of uromodulin export dynamics. Hum Mol Genet. 2003;12(24):3369-3384.

100. Storey GD. Alfred Baring Garrod (1819-1907). Rheumatology (Oxford). 2001;40(10):1189-1190.

101. Faires JS, McCarty DJ. Acute arthritis in man and dog after intrasynovial injection of sodium urate crystals. Lancet. 1962;280(7258): 682-685.

102. Pascual E, Jovani V. A quantitative study of the phagocytosis of urate crystals in the synovial fluid of asymptomatic joints of patients with gout. Br J Rheumatol. 1995;34(8):724-726.

103. Simkin PA. Concentration of urate by differential diffusion: a hypothesis for initial urate deposition. Adv Exp Med Biol. 1974;41:547-550. 
104. So A. Developments in the scientific and clinical understanding of gout. Arthritis Res Ther. 2008;10(5):221.

105. Pillinger MH, Keenan RT. Update on the management of hyperuricemia and gout. Bull NYU Hosp Jt Dis. 2008;66(3):231-239.

106. Liote F, Ea HK. Recent developments in crystal-induced inflammation pathogenesis and management. Curr Rheumatol Rep. 2007;9(3): 243-250.

107. Reginato AM, Olsen BR. Genetics and experimental models of crystalinduced arthritis. Lessons learned from mice and men: is it crystal clear? Curr Opin Rheumatol. 2007;19(2):134-145.

108. Rose DM, Liu-Bryan R. Innate immunity in triggering and resolution of acute gouty inflammation. Curr Rheumatol Rep. 2006;8(3): 209-214.

109. Koopman WJ, Moreland LW. Arthritis and Allied Conditions: A Textbook of Rheumatology. 15th ed. Philadelphia: Lippincott Williams \& Wilkins; 2005.

110. Abramson S, Hoffstein ST, Weissmann G. Superoxide anion generation by human neutrophils exposed to monosodium urate. Arthritis Rheum. 1982;25(2):174-180.

111. Terkeltaub RA, Dyer CA, Martin J, Curtiss LK. Apolipoprotein (apo) E inhibits the capacity of monosodium urate crystals to stimulate neutrophils. Characterization of intraarticular apo $E$ and demonstration of apo $E$ binding to urate crystals in vivo. J Clin Invest. 1991;87(1):20-26.

112. Akahoshi T, Murakami Y, Kitasato H. Recent advances in crystalinduced acute inflammation. Curr Opin Rheumatol. 2007;19(2): 146-150.

113. McCarty DJ Jr, Phelps P, Pyenson J. Crystal-induced inflammation in canine joints. I. An experimental model with quantification of the host response. J Exp Med. 1966;124(1):99-114.

114. Falasca GF, Ramachandrula A, Kelley KA, O'Connor CR, Reginato AJ. Superoxide anion production and phagocytosis of crystals by cultured endothelial cells. Arthritis Rheum. 1993;36(1):105-116.

115. Terkeltaub R, Zachariae C, Santoro D, Martin J, Peveri P, Matsushima K. Monocyte-derived neutrophil chemotactic factor/interleukin- 8 is a potential mediator of crystal-induced inflammation. Arthritis Rheum. 1991;34(7):894-903.

116. Duff GW, Atkins E, Malawista SE. The fever of gout: urate crystals activate endogenous pyrogen production from human and rabbit mononuclear phagocytes. Trans Assoc Am Physicians. 1983;96:234-245.

117. Martin WJ, Walton M, Harper J. Resident macrophages initiating and driving inflammation in a monosodium urate monohydrate crystalinduced murine peritoneal model of acute gout. Arthritis Rheum. 2009; 60(1):281-289.

118. Martin WJ, Harper JL. Innate inflammation and resolution in acute gout. Immunol Cell Biol. 2010;88(1):15-19.

119. Liu-Bryan R, Scott P, Sydlaske A, Rose DM, Terkeltaub R. Innate immunity conferred by Toll-like receptors 2 and 4 and myeloid differentiation factor 88 expression is pivotal to monosodium urate monohydrate crystal-induced inflammation. Arthritis Rheum. 2005;52(9): 2936-2946.

120. Ryckman C, Gilbert C, de Medicis R, Lussier A, Vandal K, Tessier PA. Monosodium urate monohydrate crystals induce the release of the proinflammatory protein S100A8/A9 from neutrophils. J Leukoc Biol. 2004;76(2):433-440.

121. Gasse P, Riteau N, Charron S, et al. Uric acid is a danger signal activating NALP3 inflammasome in lung injury inflammation and fibrosis. Am J Respir Crit Care Med. 2009;179(10):903-913.

122. Martinon F, Mayor A, Tschopp J. The inflammasomes: guardians of the body. Annu Rev Immunol. 2009;27:229-265.

123. Bianchi ME. DAMPs, PAMPs and alarmins: all we need to know about danger. J Leukoc Biol. 2007;81(1):1-5.

124. Malawista SE, Duff GW, Atkins E, Cheung HS, McCarty DJ. Crystalinduced endogenous pyrogen production. A further look at gouty inflammation. Arthritis Rheum. 1985;28(9):1039-1046.

125. Wood DD, Ihrie EJ, Dinarello CA, Cohen PL. Isolation of an interleukin-1-like factor from human joint effusions. Arthritis Rheum. 1983; 26(8):975-983.
126. di Giovine FS, Malawista SE, Nuki G, Duff GW. Interleukin 1 (IL 1) as a mediator of crystal arthritis. Stimulation of T cell and synovial fibroblast mitogenesis by urate crystal-induced IL 1. J Immunol. 1987 May 15;138(10):3213-3218.

127. Martinon F, Burns K, Tschopp J. The inflammasome: a molecular platform triggering activation of inflammatory caspases and processing of proIL-beta. Mol Cell. 2002;10(2):417-426.

128. Martinon F, Petrilli V, Mayor A, Tardivel A, Tschopp J. Goutassociated uric acid crystals activate the NALP3 inflammasome. Nature. 2006;440(7081):237-241.

129. Sidiropoulos PI, Goulielmos G, Voloudakis GK, Petraki E, Boumpas DT. Inflammasomes and rheumatic diseases: evolving concepts. Ann Rheum Dis. 2008;67(10):1382-1389.

130. Franchi L, Eigenbrod T, Munoz-Planillo R, Nunez G. The inflammasome: a caspase-1-activation platform that regulates immune responses and disease pathogenesis. Nat Immunol. 2009;10(3): 241-247.

131. Pope RM, Tschopp J. The role of interleukin-1 and the inflammasome in gout: implications for therapy. Arthritis Rheum. 2007;56(10): 3183-3188.

132. Liu-Bryan R. Intracellular innate immunity in gouty arthritis: role of NALP3 inflammasome. Immunol Cell Biol. 2010;88(1):20-23.

133. Church LD, Cook GP, McDermott MF. Primer: inflammasomes and interleukin 1beta in inflammatory disorders. Nat Clin Pract Rheumatol. 2008;4(1):34-42.

134. Petrilli V, Martinon F. The inflammasome, autoinflammatory diseases, and gout. Joint Bone Spine. 2007;74(6):571-576.

135. Liu-Bryan R, Pritzker K, Firestein GS, Terkeltaub R. TLR2 signaling in chondrocytes drives calcium pyrophosphate dihydrate and monosodium urate crystal-induced nitric oxide generation. J Immunol. 2005; 174(8):5016-5023.

136. Liu-Bryan R, Liote F. Monosodium urate and calcium pyrophosphate dihydrate (CPPD) crystals, inflammation, and cellular signaling. Joint Bone Spine. 2005;72(4):295-302.

137. Scott P, Ma H, Viriyakosol S, Terkeltaub R, Liu-Bryan R. Engagement of CD14 mediates the inflammatory potential of monosodium urate crystals. J Immunol. 2006;177(9):6370-6378.

138. Yagnik DR, Evans BJ, Florey O, Mason JC, Landis RC, Haskard DO. Macrophage release of transforming growth factor betal during resolution of monosodium urate monohydrate crystal-induced inflammation. Arthritis Rheum. 2004;50(7):2273-2280.

139. Landis RC, Yagnik DR, Florey O, et al. Safe disposal of inflammatory monosodium urate monohydrate crystals by differentiated macrophages. Arthritis Rheum. 2002;46(11):3026-3033.

140. Marcolongo R, Calabria AA, Lalumera M, Gerli R, Alessandrini C, Cavallo G. The "switch-off" mechanism of spontaneous resolution of acute gout attack. J Rheumatol. 1988;15(1):101-109.

141. Schumacher HR Jr. The pathogenesis of gout. Cleve Clin J Med. 2008; 75 Suppl 5:S2-S4.

142. Falasca GF. Metabolic diseases: gout. Clin Dermatol. 2006;24(6): 498-508.

143. ter Borg EJ, Rasker JJ. Gout in the elderly, a separate entity? Ann Rheum Dis. 1987;46(1):72-76.

144. O'Dell JR. Gout in Heberden's nodes. Arthritis Rheum. 1983;26(11): 1413-1414.

145. Molinos Normiella C, Rey Galan C, Medina Villanueva A, Concha Torre A, Menendez Cuervo S. Uric acid as a prognostic marker in critically ill patients. An Esp Pediatr. 2001;55(4):305-309.

146. Weaver J, Somani N, Bauer TW, Piliang M. Simple non-staining method to demonstrate urate crystals in formalin-fixed, paraffin-embedded skin biopsies. J Cutan Pathol. 2009;36(5):560-564.

147. Shidham V, Chivukula M, Basir Z, Shidham G. Evaluation of crystals in formalin-fixed, paraffin-embedded tissue sections for the differential diagnosis of pseudogout, gout, and tumoral calcinosis. Mod Pathol. 2001;14(8):806-810.

148. Perez-Ruiz F, Dalbeth N, Urresola A, de Miguel E, Schlesinger N. Imaging of gout: findings and utility. Arthritis Res Ther. 2009;11(3):232. 
149. Dalbeth N, McQueen FM. Use of imaging to evaluate gout and other crystal deposition disorders. Curr Opin Rheumatol. 2009;21(2): 124-131.

150. Filippucci E, Scire CA, Delle Sedie A, et al. Ultrasound imaging for the rheumatologist. XXV. Sonographic assessment of the knee in patients with gout and calcium pyrophosphate deposition disease. Clin Exp Rheumatol. 2010;28(1):2-5.

151. de Avila Fernandes E, Kubota ES, Sandim GB, Mitraud SA, Ferrari AJ, Fernandes AR. Ultrasound features of tophi in chronic tophaceous gout. Skeletal Radiol. 2010. [Epub ahead of print].

152. Thiele RG, Schlesinger N. Diagnosis of gout by ultrasound. Rheumatology (Oxford). 2007;46(7):1116-1121.

153. Carter JD, Kedar RP, Anderson SR, et al. An analysis of MRI and ultrasound imaging in patients with gout who have normal plain radiographs. Rheumatology (Oxford). 2009;48(11):1442-1446.

154. Kunkel G, Kaeley G, Thiele R. Comment on: an analysis of MRI and ultrasound imaging in patients with gout who have normal plain radiographs. Rheumatology (Oxford). 2010;49(5):1022-1023; author reply $1023-1024$.

155. Neogi T, Hunter DJ, Chaisson CE, Allensworth-Davies D, Zhang Y. Frequency and predictors of inappropriate management of recurrent gout attacks in a longitudinal study. $J$ Rheumatol. 2006;33(1): 104-109.

156. Terkeltaub RA, Furst DE, Bennett K, Kook KA, Crockett RS, Davis MW. High versus low dosing of oral colchicine for early acute gout flare: Twenty-four-hour outcome of the first multicenter, randomized, double-blind, placebo-controlled, parallel-group, dose-comparison colchicine study. Arthritis Rheum. 2010;62(4):1060-1068.

157. Pharma U. Colcrys Official Prescribing Information. 2010 May: Official Prescribing Information. http://colcrys.com/assets/pdf/COLCRYS_ Full_Prescribing_Information.pdf. Accessed 2010 Aug 28.

158. Molad Y. Update on colchicine and its mechanism of action. Curr Rheumatol Rep. 2002;4(3):252-256.

159. Chen YJ, Huang SM, Liu CY, Yeh PH, Tsai TH. Hepatobiliary excretion and enterohepatic circulation of colchicine in rats. Int J Pharm. 2008;350(1-2):230-239.

160. Montseny JJ, Meyrier A, Gherardi RK. Colchicine toxicity in patients with chronic renal failure. Nephrol Dial Transplant. 1996;11(10): 2055-2058.

161. Schiff D, Drislane FW. Rapid-onset colchicine myoneuropathy. Arthritis Rheum. 1992;35(12):1535-1536.

162. Fiehn C, Zeier M. Successful treatment of chronic tophaceous gout with infliximab (Remicade). Rheumatol Int. 2006;26(3):274-276.

163. Tausche AK, Richter K, Grassler A, Hansel S, Roch B, Schroder HE. Severe gouty arthritis refractory to anti-inflammatory drugs: treatment with anti-tumour necrosis factor alpha as a new therapeutic option. Ann Rheum Dis. 2004;63(10):1351-1352.

164. Meng ZH, Hudson AP, Schumacher HR Jr, Baker JF, Baker DG. Monosodium urate, hydroxyapatite, and calcium pyrophosphate crystals induce tumor necrosis factor-alpha expression in a mononuclear cell line. J Rheumatol. 1997;24(12):2385-2388.

165. di Giovine FS, Malawista SE, Thornton E, Duff GW. Urate crystals stimulate production of tumor necrosis factor alpha from human blood monocytes and synovial cells. Cytokine mRNA and protein kinetics, and cellular distribution. J Clin Invest. 1991;87(4):1375-1381.

166. So A, de Smedt T, Revaz S, Tschopp J. A pilot study of IL-1 inhibition by anakinra in acute gout. Arthritis Res Ther. 2007;9(2):R28.

167. Singh D, Huston KK. IL-1 inhibition with anakinra in a patient with refractory gout. J Clin Rheumatol. 2009;15(7):366.

168. Gratton SB, Scalapino KJ, Fye KH. Case of anakinra as a steroidsparing agent for gout inflammation. Arthritis Rheum. 2009;61(9): $1268-1270$.

169. Terkeltaub R, Sundy JS, Schumacher HR, et al. The interleukin 1 inhibitor rilonacept in treatment of chronic gouty arthritis: results of a placebo-controlled, monosequence crossover, non-randomised, singleblind pilot study. Ann Rheum Dis. 2009;68(10):1613-1617.
170. So A, de Meulemeester M, Pikhlak A, et al. Canakinumab for the treatment of acute flares in difficult-to-treat gouty arthritis: results of a multicenter, phase II, dose-ranging study. Arthritis Rheum. 2010; 62(10):3064-3076.

171. Study of Tranilast Alone or in Combination With Allopurinol in Subjects With Hyperuricemia. 2010; http://clinicaltrials.gov/ct2/show/N CT01052987?intr $=$ Tranilast\&rank=2. Accessed 2010 Sep 1.

172. Higgs G. Is PDE4 too difficult a drug target? Curr Opin Investig Drugs. 2010;11(5):495-498.

173. Apremilast Therapy for Acute Gouty Arthritis. 2010; http:// clinicaltrials.gov/ct2/show/NCT00997581?term=apremilast\& rank=11. Accessed 2010 Sep 1.

174. Favre L, Glasson P, Riondel A, Vallotton MB. Interaction of diuretics and non-steroidal anti-inflammatory drugs in man. Clin Sci (Lond). 1983;64(4):407-415.

175. Favre L, Glasson P, Vallotton MB. Reversible acute renal failure from combined triamterene and indomethacin: a study in healthy subjects. Ann Intern Med. 1982;96(3):317-320.

176. Varughese GI, Varghese AI. Colchicine myoneuropathy: the role of rhabdomyolysis. Nephrology (Carlton). 2006;11(5):481-482; author reply 482.

177. Lai IC, Cheng CY, Chen HH, Chen WY, Chen PY. Colchicine myoneuropathy in chronic renal failure patients with gout. Nephrology (Carlton). 2006;11(2):147-150.

178. Kuncl RW, Duncan G, Watson D, Alderson K, Rogawski MA, Peper M. Colchicine myopathy and neuropathy. N Engl J Med. 1987; 316(25):1562-1568.

179. Uloric Full Prescribing Information. 2009; http://general.takedap harm.com/content/file/pi.pdf?applicationcode $=6$ C7C39D8-5D09453B-BF30-696A4AB88E62\&FileTypeCode=ULORICPI. Accessed 2010 Aug 30.

180. Kissin EY, Nishio J, Yang M, et al. Self-directed learning of basic musculoskeletal ultrasound among rheumatologists in the United States. Arthritis Care Res (Hoboken). 2010;62(2):155-160.

181. Filippucci E, Riveros MG, Georgescu D, Salaffi F, Grassi W. Hyaline cartilage involvement in patients with gout and calcium pyrophosphate deposition disease. An ultrasound study. Osteoarthritis Cartilage. 2009;17(2):178-181.

182. Choi HK. A prescription for lifestyle change in patients with hyperuricemia and gout. Curr Opin Rheumatol. 2010;22(2):165-172.

183. Doherty M. New insights into the epidemiology of gout. Rheumatology (Oxford). 2009;48 Suppl 2:ii2-ii8.

184. Cutler DM, Glaeser EL, Shapiro JM. Why have Americans become more obese? J Econ Perspect. 2003;17:93-118.

185. Statistics Related to Overweight and Obesity NIH Publication Number 04-4158. 2010; http://win.niddk.nih.gov/statistics/. Accessed 2010 Aug 1.

186. Choi HK, Atkinson K, Karlson EW, Curhan G. Obesity, weight change, hypertension, diuretic use, and risk of gout in men: the health professionals follow-up study. Arch Intern Med. 2005;165(7): $742-748$.

187. Choi JW, Ford ES, Gao X, Choi HK. Sugar-sweetened soft drinks, diet soft drinks, and serum uric acid level: The Third National Health and Nutrition Examination Survey. Arthritis Rheum. 2008;59(1): 109-116.

188. Choi HK, Curhan G. Soft drinks, fructose consumption, and the risk of gout in men: prospective cohort study. BMJ. 2008;336(7639): 309-312.

189. Schlesinger N. Dietary factors and hyperuricaemia. Curr Pharm Des. 2005;11(32):4133-4138

190. Kerndt PR, Naughton JL, Driscoll CE, Loxterkamp DA. Fasting: the history, pathophysiology and complications. West J Med. 1982;137(5): 379-399.

191. Choi HK, Atkinson K, Karlson EW, Willett W, Curhan G. Alcohol intake and risk of incident gout in men: a prospective study. Lancet. 2004;363(9417):1277-1281. 
192. Jacob RA, Spinozzi GM, Simon VA, et al. Consumption of cherries lowers plasma urate in healthy women. J Nutr. 2003;133(6): 1826-1829.

193. Howatson G, McHugh MP, Hill JA, et al. Influence of tart cherry juice on indices of recovery following marathon running. Scand J Med Sci Sports. 2009. [Epub ahead of print].

194. Kelley DS, Rasooly R, Jacob RA, Kader AA, Mackey BE. Consumption of Bing sweet cherries lowers circulating concentrations of inflammation markers in healthy men and women. JNutr. 2006;136(4): 981-986.

195. USDA National Nutrient Database for Standard Reference. Nutrient Data Laboratory Home Page, http://www.ars.usda.gov/ba/bhnrc/ndl. US Department of Agriculture; 2010. http://www.ars.usda.gov/ba/ bhnrc/ndl. Accessed 2010 Oct 8.

196. Blau LW. Cherry diet control for gout and arthritis. Tex Rep Biol Med. 1950;8(3):309-311.

197. Stein HB, Hasan A, Fox IH. Ascorbic acid-induced uricosuria. A consequency of megavitamin therapy. Ann Intern Med. 1976;84(4): 385-388.

198. Choi HK, Gao X, Curhan G. Vitamin C intake and the risk of gout in men: a prospective study. Arch Intern Med. 2009;169(5):502-507.

199. Gao X, Curhan G, Forman JP, Ascherio A, Choi HK. Vitamin C intake and serum uric acid concentration in men. J Rheumatol. 2008;35(9): 1853-1858.

200. McGill NW. Gout and other crystal-associated arthropathies. Baillieres Best Pract Res Clin Rheumatol. 2000;14(3):445-460.

201. Sarawate CA, Brewer KK, Yang W, et al. Gout medication treatment patterns and adherence to standards of care from a managed care perspective. Mayo Clin Proc. 2006;81(7):925-934.

202. Riedel AA, Nelson M, Wallace K, Joseph-Ridge N, Cleary M, Fam AG. Prevalence of Comorbid Conditions and Prescription Medication Use Among Patients With Gout and Hyperuricemia in a Managed Care Setting. J Clin Rheumatol. 2004;10(6):308-314.

203. Riedel AA, Nelson M, Joseph-Ridge N, Wallace K, MacDonald P, Becker M. Compliance with allopurinol therapy among managed care enrollees with gout: a retrospective analysis of administrative claims. J Rheumatol. 2004;31(8):1575-1581.

204. Reinders MK, Haagsma C, Jansen TL, et al. A randomised controlled trial on the efficacy and tolerability with dose escalation of allopurinol $300-600 \mathrm{mg}$ /day versus benzbromarone $100-200 \mathrm{mg} /$ day in patients with gout. Ann Rheum Dis. 2009;68(6):892-897.

205. Dalbeth N, Stamp L. Allopurinol dosing in renal impairment: walking the tightrope between adequate urate lowering and adverse events. Semin Dial. 2007;20(5):391-395.

206. Shalom R, Rimbroth S, Rozenman D, Markel A. Allopurinol-induced recurrent DRESS syndrome: pathophysiology and treatment. Ren Fail. 2008;30(3):327-329.

207. Fam AG, Lewtas J, Stein J, Paton TW. Desensitization to allopurinol in patients with gout and cutaneous reactions. Am J Med. 1992;93(3): 299-302.

208. Lee SS, Lin HY, Wang SR, Tsai YY. Allopurinol hypersensitivity syndrome. Zhonghua Min Guo Wei Sheng Wu Ji Mian Yi Xue Za Zhi. 1994;27(3):140-147.

209. Lupton GP, Odom RB. The allopurinol hypersensitivity syndrome. J Am Acad Dermatol. 1979;1(4):365-374.

210. Roujeau JC, Kelly JP, Naldi L, et al. Medication use and the risk of Stevens-Johnson syndrome or toxic epidermal necrolysis. $N$ Engl J Med. 1995;333(24):1600-1607.

211. Markel A. Allopurinol-induced DRESS syndrome. Isr Med Assoc J. 2005;7(10):656-660.

212. Hung SI, Chung WH, Liou LB, et al. HLA-B*5801 allele as a genetic marker for severe cutaneous adverse reactions caused by allopurinol. Proc Natl Acad Sci U S A. 2005;102(11):4134-4139.

213. Zyloprim ${ }^{\circledR}$ Official Prescribing Information. 2003; http://www. prometheuspatients.com/PDF/Zyloprim.pdf. Accessed 2010 Aug 30.
214. Chao J, Terkeltaub R. A critical reappraisal of allopurinol dosing, safety, and efficacy for hyperuricemia in gout. Curr Rheumatol Rep. 2009;11(2):135-140.

215. Gaffo AL, Saag KG. Management of hyperuricemia and gout in CKD. Am J Kidney Dis. 2008;52(5):994-1009.

216. Murrell GA, Rapeport WG. Clinical pharmacokinetics of allopurinol. Clin Pharmacokinet. 1986;11(5):343-353.

217. Hande KR, Noone RM, Stone WJ. Severe allopurinol toxicity. Description and guidelines for prevention in patients with renal insufficiency. Am J Med. 1984;76(1):47-56.

218. Bellamy N, Gilbert JR, Brooks PM, Emmerson BT, Campbell J. A survey of current prescribing practices of antiinflammatory and urate lowering drugs in gouty arthritis in the province of Ontario. J Rheumatol. 1988;15(12):1841-1847.

219. Dalbeth N, Kumar S, Stamp L, Gow P. Dose adjustment of allopurinol according to creatinine clearance does not provide adequate control of hyperuricemia in patients with gout. J Rheumatol. 2006;33(8):1646-1650.

220. Vazquez-Mellado J, Morales EM, Pacheco-Tena C, Burgos-Vargas R. Relation between adverse events associated with allopurinol and renal function in patients with gout. Ann Rheum Dis. 2001;60(10): 981-983.

221. Ifudu O, Tan CC, Dulin AL, Delano BG, Friedman EA. Gouty arthritis in end-stage renal disease: clinical course and rarity of new cases. $\mathrm{Am}$ J Kidney Dis. 1994;23(3):347-351.

222. Schreiner O, Wandel E, Himmelsbach F, Galle PR, Marker-Hermann E. Reduced secretion of proinflammatory cytokines of monosodium urate crystal-stimulated monocytes in chronic renal failure: an explanation for infrequent gout episodes in chronic renal failure patients? Nephrol Dial Transplant. 2000;15(5):644-649.

223. Garg JP, Chasan-Taber S, Blair A, et al. Effects of sevelamer and calcium-based phosphate binders on uric acid concentrations in patients undergoing hemodialysis: a randomized clinical trial. Arthritis Rheum. 2005;52(1):290-295.

224. Stamp L, Ha L, Searle M, O’Donnell J, Frampton C, Chapman P. Gout in renal transplant recipients. Nephrology (Carlton). 2006;11(4): 367-371.

225. Stamp L, Searle M, O’Donnell J, Chapman P. Gout in solid organ transplantation: a challenging clinical problem. Drugs. 2005;65(18) 2593-2611.

226. Siegenthaler-Zuber G. Which uric acid value is in need of treatment? Schweiz Med Wochenschr. 1976;106(14):487-491.

227. Liang MH, Fries JF. Asymptomatic hyperuricemia: the case for conservative management. Ann Intern Med. 1978;88(5):666-670.

228. Dawson J, Quinn T, Walters M. Uric acid reduction: a new paradigm in the management of cardiovascular risk? Curr Med Chem. 2007;14(17): 1879-1886.

229. Becker MA, Schumacher HR Jr, Wortmann RL, et al. Febuxostat, a novel nonpurine selective inhibitor of xanthine oxidase: a twenty-eight-day, multicenter, phase II, randomized, double-blind, placebo-controlled, dose-response clinical trial examining safety and efficacy in patients with gout. Arthritis Rheum. 2005;52(3): 916-923.

230. Becker MA, Schumacher HR Jr, Wortmann RL, et al. Febuxostat compared with allopurinol in patients with hyperuricemia and gout. N Engl J Med. 2005;353(23):2450-2461.

231. Febuxostat Phase 3 Clinical Trials Study NCT00174915. Takeda Pharmaceuticals; 2009. http://clinicaltrials.gov/ct2/show/results/NC T00174915?term $=$ gout\&rank=9\&sect=X6015\#outcome1. Accessed 2010 Jun 21.

232. Terkeltaub RA. Clinical practice. Gout. N Engl J Med. 2003;349(17): 1647-1655.

233. Reinders MK, van Roon EN, Jansen TL, et al. Efficacy and tolerability of urate-lowering drugs in gout: a randomised controlled trial of benzbromarone versus probenecid after failure of allopurinol. Ann Rheum Dis. 2009;68(1):51-56. 
234. Lee MH, Graham GG, Williams KM, Day RO. A benefit-risk assessment of benzbromarone in the treatment of gout. Was its withdrawal from the market in the best interest of patients? Drug Saf. 2008;31(8):643-665.

235. Takahashi S, Moriwaki Y, Yamamoto T, Tsutsumi Z, Ka T, Fukuchi M. Effects of combination treatment using anti-hyperuricaemic agents with fenofibrate and/or losartan on uric acid metabolism. Ann Rheum Dis. 2003;62(6):572-575.

236. Terkeltaub R. Gout. Novel therapies for treatment of gout and hyperuricemia. Arthritis Res Ther. 23 2009;11(4):236.
237. Lasko B, Sheedy B, Hingorani V, et al. RDEA594, a novel uricosuric agent, significantly reduced serum urate levels and was well tolerated in a phase 2a pilot study in hyperuricemic gout patients. 2009 American College of Rheumatology Annual Scientific Meeting. Philadelphia, PA; 2009.

238. Ardea Biosciences Announces positive results from a Phase 1 Study of RDEA594. Medical News Today 2009; http://www.medicalnewstoday. com/articles/135285.php. Accessed 2010 Aug 30.

\section{Publish your work in this journal}

The International Journal of Nephrology and Renovascular Disease is an international, peer-reviewed open-access journal focusing on the pathophysiology of the kidney and vascular supply. Epidemiology, screening, diagnosis, and treatment interventions are covered as well as basic science, biochemical and immunological studies. The journal welcomes original research, clinical studies, reviews \& evaluations, expert opinion and commentary, case reports and extended reports. The manuscript management system is completely online and includes a very quick and fair peerreview system, which is all easy to use. Visit http://www.dovepress.com/ testimonials.php to read real quotes from published authors.

Submit your manuscript here: http://www.dovepress.com/international-journal-of-nephrology-and-renovascular-disease-journal 